\title{
A qualitative study exploring the experience of psychotherapists working with birth trauma
}

\author{
Elizabeth Gough, Vaitsa Giannouli \\ Department of Psychology, Mediterranean College-University of Derby, Thessaloniki, Greece
}

\begin{abstract}
As many as $45 \%$ of women experience birth trauma. Psychotherapists' knowledgeable insights are largely absent in literature, and therefore the objective of this research is to gain a comprehensive understanding of how psychotherapists in the UK experience the therapeutic process when working with women who have experienced a traumatic birth. Interpretive Phenomenological Analysis (IPA) was employed to examine the data coming from psychotherapists working with birth trauma. Three ostensible areas of focus were revealed: i) Hearing the story: discovering the altered-self, ii) Working with the story: enabling redemption of the altered-self, and iii) Professional challenges and the wider story: advocating for the altered-self. Birth trauma commonly leads to an altered sense of self, intertwined with a perception of loss regarding the birth experience and autonomy. Working with the client's birth story, to enable redemption
\end{abstract}

Correspondence: Vaitsa Giannouli, MSc Integrative Counselling and Psychotherapy, Mediterranean College \& Derby University, Thessaloniki, Greece.

E-mail: giannouliv@hotmail.com

Key words: Birth trauma; psychotherapist; subjective birth experience; Interpretive Phenomenological Analysis (IPA).

Contributions: EG and VG jointly initiated the study and planned the research design. EG collected the data and wrote the first version of the paper. VG prepared the final version of the article. All the authors critically read and revised the final version of the manuscript.

Conflict of interest: The authors declare no conflict of interest.

Funding: None.

Ethics approval and consent to participate: The study was approved by Ethical Review Committee, Derby University and informed consent was obtained.

Availability of data and materials: All data and materials are available within the text.

Received for publication: 13 June 2020.

Revision received: 17 July 2020.

Accepted for publication: 19 November 2020.

This work is licensed under a Creative Commons AttributionNonCommercial 4.0 International License (CC BY-NC 4.0).

(C) Copyright: the Author(s), 2020

Licensee PAGEPress, Italy

Health Psychology Research 2020; 8:9718

doi:10.4081/hpr.2020.9178 and restore reasoning, is integral to the therapeutic process. Stabilisation and consideration of the presence of the baby are also significant. Integrating approaches produces positive outcomes. There is a purported gap in NHS services, professionals either lacking knowledge and misdiagnosing, or being limited by the emphasis placed on Cognitive Behavioural Therapy. For the therapeutic process consider: the sense of loss associated with the birth; working with the client's birth story to enable redemption and restore reasoning; the impact of the presence of the baby and the need for stabilisation; birth trauma as unique. For frontline health professionals: implementing existing screening protocols and undergoing training to recognise birth trauma may reduce misdiagnosis.

\section{Introduction}

It is only in the last 10-20 years that birth trauma has begun to be explored in research, historically focusing on postnatal depression and puerperal psychosis (Ayers, 2014; Gamble \& Creedy, 2004; Peeler, Chung, Stedmon, \& Skirton, 2013). The National Institute for Health and Care Excellence (NICE) define a traumatic birth as including "births, whether preterm or full term, which are physically traumatic (for example, instrumental deliveries or emergency caesarean sections, severe perineal tears, postpartum haemorrhage) and births that are experienced as traumatic, even when the delivery is obstetrically straightforward" (NICE, 2014). The reported prevalence varies dramatically, $6-45 \%$ of women describing their birth as 'traumatic' (Alcorn, O'Donovan, Patrick, Creedy, \& Devilly, 2010; Ayers, Joseph, McKenzie-McHarg, Slade, \& Wijma, 2008; Beck, 2006; Boorman, Devilly, Gamble, Creedy, \& Fenwick, 2014; Soet, Brack, \& DiIorio, 2003), possibly because births considered to be clinically 'traumatic' produce lower figures than those women themselves deem 'traumatic' (Blainey \& Slade, 2015; Ayers et al., 2008). Perception of birth trauma is complex: a significant intervention, such as a forceps delivery, may be considered traumatic by health professionals, yet a woman may believe her birth to have been traumatic because she was refused an assisted delivery (Briddon, Isaac \& Slade, 2015). Inconsistencies can also be observed where a woman has an uncomplicated delivery, but elements of her birth-plan were not fulfilled, leading to a sense of failure, a perception of shattereddreams, loss and disenfranchised grief (DeGroot \& Vic, 2017). It is reported that a loss of control and negative interactions with health professionals may also lead to a perception of birth as being traumatic (Beck, 2009). Perhaps it is partly due to this confusion that a proposed $25 \%$ of cases go unnoticed (Czarnocka \& Slade, 2000). Women subsequently report panic attacks, intrusive images and flashbacks, avoidance of triggers, anxiety, intense negative emotions, an altered sense of self, lack of interest in activities, isolation, depression, suicidal ideation, hyper-vigilant behaviour, and problems in relationships (Ammerman, Putnam, Chard, Stevens, \& Van Ginkel, 2012; Ayers, 2014; Beck, 2009; Briddon et al., 2015; Fenech \& Thomson, 2014). Disruption of mother-infant 
bonding is also reported, as well as tokophobia relating to potential future births (Beck, 2009; Fenech \& Thomson, 2014; Nicholls \& Ayers, 2007; Simpson \& Catling, 2015). Symptoms frequently fulfil the DSMV (American Psychiatric Association, 2013) criteria for Post-Traumatic Stress Disorder (PTSD) (Ayers, 2014), which demands that the event, the birth, involves perceived threat of serious injury or death either to the individual or a close family member, the baby. Boorman et al. (2014), found $14.3 \%$ of women experienced this threat perception during birth. Women's experiences of birth trauma, and those of midwives supporting this client group, have been researched in detail (Baxter, McCourt, \& Jarrett, 2014; Reed, Fenwick, Hauck, Gamble, \& Creedy, 2014; Simpson \& Catling, 2015). Following birth trauma, initial National Health Service (NHS) support comes via maternity debriefing services, usually staffed by midwives. While recognising some positive elements, literature indicates a general unease that those carrying out the debriefing may not have the necessary psychological understanding and skills to work with trauma (Erskine, 2013; Kershaw, Jolly, Kalvinder, \& Ford, 2005; McKenzie-McHarg, 2004; Rowan, Bick, \& Bastos 2007) and that uniform-clad midwives, debriefing in hospitals where the trauma took place, may affect re-traumatisation (Sltibniewski-Woods, 2011). There are suggestions that traditional debriefing is inefficient in reducing psychological problems following difficult births and may complicate things further (Baxter et al., 2014; Gamble, Creedy, \& Moyle, 2004; Sheen \& Slade, 2015). The provision of professional psychological support is repeatedly advised (Cunen, McNeill, \& Murray, 2014; DikmanYildiz, Ayers, \& Phillips, 2017; Fenech \& Thomson, 2014; Turkstra et al., 2015). General trauma research outlines the risks of re-traumatising individuals, consistently recommending that any professionals working with trauma must be capable of stabilising clients who become hyper-anxious during sessions (Duckworth \& Follette, 2012; Fisher, 2011). The ability to skilfully apply research findings also illustrates a need for adequately qualified professionals. For example, Beck, Storrs, and Watson (2016) discovered a potential for positive personal growth following birth trauma, determining that clinicians could share this information to provide hope for those struggling with trauma symptoms but noting it would require gentle, informed handling, with a full understanding of that individual's case, in order not to create false expectations or negatively impact the woman's emotional state (Beck et al., 2016).

The call for further research, to determine what the aforementioned 'professional support' might look like and to help identify those at risk of Post-Traumatic Stress, recurs throughout the literature (Ayers, 2007; Ayers \& Delicate, 2016; Blainey \& Slade, 2015; Dikmen-Yildiz et al., 2017; Fenech \& Thomson, 2014; Peeler et al., 2013). Indeed, research in this area may be beneficial for the wider healthcare profession. For example, a multidisciplinary clinical trial found encouraging women to bond with their babies, specifically in the hour following birth, was therapeutic for relieving post-traumatic stress where women had experienced traumatic births (Abdollahpour, Khosravi, \& Bolbolhaghighi, 2016), information valuable not only for perinatal psychotherapists, when preparing women for birth, but also for midwives and obstetricians. DeGroot \& Vic (2017) found that failed birth plans may cause trauma responses postnatally, recommending postnatal women be routinely asked if their birth plan was followed. Again, this information would be beneficial across the disciplines, relating to the detection of psychological stress following birth trauma. Fenech \& Thomson (2014) suggest that the significance of birth trauma is recognised multi-professionally but note further research is required regarding the timings and types of approaches and interventions used with this client group. Existing literature on this subject currently consists more of conjecture than professional research (Peeler et al., 2013).

Cognitive Behavioural Therapy (CBT) is exceptional, across the huge variety of psychological approaches, because it lends itself to research, giving it an empirical base (Beck \& Dozois, 2011). It is difficult to evaluate its application and effectiveness, in a given circumstance, with other schools, who are not able to generate empirical data or material of a comparable nature (Hofmann, Asnaani, Vonk, Sawyer, \& Fang 2012; Ruotsalainen, Verbeek, Mariné, \& Serra, 2014). It is suggested that consequently, in the context of an increasingly litigious UK society and NICE's evidence-driven focus on practice, it was natural that CBT would be promoted ahead of other approaches for use in the NHS (Rachman \& Wilson, 2008). The Government's Improving Access to Psychological Therapies (IAPT) programme (DOH, 2007), led to the training of thousands of new CBT therapists, making it the common psychotherapeutic approach available on the NHS (Clark, 2011). It consequently receives the majority of funding for research and an apparent elevation above other schools of thought (Scott, 2010). This has led to a backlash amongst professionals and it is therefore worth noting the possibility that this may skew their opinions about the efficacy of CBT interventions for birth trauma. Regardless, it is true that, within the literature discovered, a significant comparative drop in the quantity of data for other approaches is noted. Effective postnatal social support appears to be an important factor in reducing the negative impact of birth trauma (Dikman-Yildiz et al., 2017; Furuta, Sandall, Cooper, \& Bick, 2016). It follows, therefore, that humanistic approach interventions, such as validation and the 'acceptance' and 'empathetic understanding' elements of Rogers' (1957) core conditions, have been shown to be beneficial for this client group (Baxter et al., 2014; Gamble \& Creedy, 2004; Gamble et al., 2004; McKenzieMcHarg, 2004). Particularly given that when women do attempt to access that desired empathy and support from their peers, their emotional pain is often disenfranchised in an apparent one-upping, with others expressing their own birth story as being equally or more traumatic (DeGroot \& Vic, 2017). Women who have experienced birth trauma appear to have a strong need to tell their story (Beck \& Driscoll, 2006; Kleimann, 2017) and the Rogerian therapist is in an excellent position to meet such a need, utilising active listening, paraphrasing and reflection of feeling (Baxter et al., 2014). The understanding of 'self' can be greatly challenged through traumatic birth, perceived disempowerment being common (Furuta et al., 2016), which suggests use of the PersonCentred Approach (PCA) may be beneficial. Unfortunately, very little literature exists around the use of these approaches with birth trauma. Briddon et al. (2015) inferred, from their findings, that it is not necessarily the trauma nor the occurrence of involuntary memories that cause PTSD symptoms, but instead the consequent response and distress experienced due to the presence of the memory. They advocate the use of 'normalising' those memories alongside the development of mindfulness and acceptance, techniques found in multiple approaches but particularly CBT, Acceptance and Commitment Therapy, Dialectical Behavioural Therapy, MetaCognitive Therapy (Wells \& Colbear, 2012) and Mindfulness itself, Mindfulness also being endorsed by Poleshuck \& Woods (2014). An up-and-coming method for working with the emotional distress caused by the memory of the trauma is the Rewind Technique, from the Human Givens Approach (HGA) and grounded in Neurolinguistic Programming (NLP), which combines cognitive-behavioural and humanistic therapies with hypnosis. Literature suggests this technique may be particularly effective for use with birth trauma (Guy \& Guy, 2009; Lovell \& Richards, 1995; 
Simpson \& Dryden, 2011; Slater, 2015). The use of Emotional Freedom Technique (EFT), rooted in mind-body psychology, is encouraged for the release of tension and anxiety following birth trauma (Bromley, Hollins Martin, \& Patterson, 2017; Grigg, 2005; Highsmith, 2016; King, 2015) and Babette Rothschild's (2000) work with Somatic Trauma Therapy is also advocated as helpful (Barratt, 2010; Mayer, 2015). Although there is currently little empirical evidence to support the use of either Psychophysiology or the Rewind technique with birth trauma, their increasing popularity suggests research will be forthcoming.

An integrative approach may therefore be a positive alternative to pure CBT, but further investigation of approaches and outcomes is required (Ayers, 2014; Baxter et al., 2014; Blainey \& Slade, 2015; Fenech \& Thomson, 2014; Lapp, Agbokou, Peretti, \& Ferreri, 2010). There is growth in research, particularly regarding predicting and preventing birth trauma, alongside the development of screening tools and a call for them to be used as part of standard postnatal care (Beck, 2009; Geller \& Stasko, 2017). Such tools would assist frontline healthcare staff lacking adequate training and understanding, who often misdiagnose birth trauma as postnatal depression or anxiety (Speier, 2017; White, Matthey, Boyd, \& Barnett, 2006). It is suggested that what is missing, in research, relates to counselling strategies, the possible processes of therapy on offer and the general management of women following birth trauma (Alder, Stadlmyar, Tschudin, \& Bitzer, J. 2006; Beck, 2009, Lapp et al., 2010). Furthermore, significantly absent is the voice of counsellors and psychotherapists themselves, who are perfectly positioned to give important phenomenological insight from their own experiences of working with women who have experienced birth trauma (Baxter et al., 2014; Poleshuck \& Woods, 2014). The overall lack of agreement in the literature highlights an apparent ambiguity and inconsistency regarding care provision subsequent to birth trauma (Alder et al., 2006; Fenech \& Thomson, 2014; Gamble \& Gamble, 2004; Lapp et al., 2010; Peeler et al., 2013; Rowan et al., 2007; Zimmerman, 2013). Peeler et al. (2013) recommend the development of a universal PTSD framework, particular to perinatal women. NICE (2014) guidelines provide a pathway for those working within postnatal mental health but research describes a general lack of resources and training to treat PTSD postnatally (Ayers et al., 2008; Fenech \& Thomson, 2014). It was hoped that the fluctuations in the standard, consistency and availability of therapy for birth trauma, would be addressed by that DOH (2013) pledge to have specialist perinatal mental health staff in all maternity units by 2017. At this point, it is not possible to know how widely or successfully that has been implemented. Where specialist training has taken place, it is likely to be in CBT, and for those who do not find CBT helpful, other forms of therapy may only be accessed if paid for privately and therefore remain inaccessible to many (Scott, 2010). There are NHS Trusts who provide other approaches, such as PDA or PCA, but this is not in keeping with NICE guidelines and is consequently less common (Murphy, Archard, Regel, \& Joseph, 2013; Scott, 2010). It appears that to have access and choice, in personalised professional care, women must pay for it, the alternative being to rely on the "poorly funded patchy service provision" available in the NHS (NCT, 2015, p.10).

\section{Rationale}

Women's individual experiences of birth trauma are well documented (Baxter et al., 2014) and there is an overwhelming voice, from a wide-spectrum, calling for more to be done to help these women (Ayers, 2007; Ayers et al., 2015; Blainey \& Slade, 2015; Boots Family Trust, 2014; BPS DCP, 2016; BTA, 2017; Fenech \& Thompson, 2014; McKenzie-McHarg \& Poote, 2015), but there is a fundamental absence of unified thought relating to the 'how' (Peeler et al., 2013; Scott, 2010). Disagreement amongst the schools of psychological thought is not by any means a new phenomenon (Jones-Smith, 2011; Sommers-Flanagan \& SommersFlanagan, 2015) but, here, the issue goes beyond the differences in approach and philosophy. There seems to be a significant gap in the research, a lack of important insight from therapists regarding their experiences of how to work with this client group and which approaches, interventions, and techniques appear to be most effective in providing positive outcomes (Baxter et al., 2014; Beck, 2009; Poleshuck \& Woods, 2014). This study may therefore be worthwhile by being informative, providing information to aid professionals working with this client group, but also partly transformative, supporting further research that aims to address the gap in care provided nationally.

\section{Research question}

Based on the above literature coming from the UK, a number of questions arise taking the form of a basic qualitative one: How psychotherapists in the UK experience the therapeutic process when working with women who have experienced a traumatic birth? No specific hypotheses were tested (as they are suitable for quantitative methodology).

\section{Methods}

\section{Participants}

Purposive sampling was used. This is effective for Interpretive Phenomenological Analysis (IPA) because it allows the selection of participants who have suitable qualifications and relevant experience (Cresswell, 2007; Giannouli, 2017). Ethical approval was granted by the University of Derby Ethics Committee, 2018.

The aim was to have 4-8 participants, the sample size high enough to gain an in-depth understanding of their experience without acquiring repetitive data (Sandelowski, 1995). Professional search sites, the NHS website and specialist perinatal websites, were used to obtain information about potential participants with the greatest experience to draw from (Table 1). Invitation letters, and a further follow-up email after a 1 month, were sent to 24 pri-

Table 1. Inclusion/exclusion criteria for participants.

Inclusion criteria

Qualified to a minimum of advanced diploma level counsellor, clinical psychologist or psychotherapist within the UK, providing private or public services.

Accredited by or Registered with a Professional Body such as BACP, BPS, UKCC. Minimum of 3 years professional experience.

Provided therapy for women who have experienced traumatic birth.

Agree to audio-recording, the recordings being destroyed within 2 years.

\section{Exclusion criteria}

Personally had a birth experience which he or she deems to have been traumatic 
vate psychotherapists, who specialise in trauma or perinatal issues, and to 17 NHS perinatal psychotherapists. Most people practising in this field are women, consequently only 3 men were approached. Of the 41 therapists invited to participate, 15 replied; 6 declined due to work/family commitments or conflicts with their own research. Two more were excluded for not meeting the inclusion criteria. Another dropped-out due to illness and declined to reschedule. Six participants were therefore gained, fulfilling the aim. All 6 participants are female, and all declared themselves to be perinatal or birth trauma specialists. Four are educated to Masters level and 2 to Advanced Diploma level, and all are accredited by or registered with professional bodies. All 6 participants work in private practice but 4 of them also work or worked for the NHS in their capacity as counsellors, psychotherapists or clinical psychologists. 5 integrate psychological approaches and 1 works solely with CBT. Their length of experience in clinical practice ranges from 3 to 20 years.

\section{Data Collection}

Semi-structured interviews were ideal for obtaining the relevant, rich verbal accounts which IPA requires for thorough analysis and meaningful discussion (Smith \& Osborn, 2007). This form of interview, as opposed to inflexibly structured interviews or single monologue narratives, gave participants the space to answer questions as fully as they wished, explaining their experiences on and in their own terms (Bernard \& Ryan, 2010). Individual interviews were preferable to focus groups, being more practicable and the participants accounts being unaffected by the presence and perceptions of peers (Lloyd-Evans, 2006). The use of an interview schedule (Figure 1) allowed careful development of relevant and mean-

Follow $\mathrm{Up}=\mathrm{F}-\mathrm{U}$

Icebreaker \& Overview (4mins):

1. Short review of subject area and purpose of research.

2. Key information, how long the interview will take, can choose not to answer a question, take a break or withdraw from the interview at any time.

\section{Relating to $1^{\text {st }}$ Objective (10 mins):}

3. Can you tell me how you assess your clients?

May F-U. with prompts re: history-taking, risk assessment.

4. I'm wondering if there are any common factors in the histories of these clients (other than experiencing traumatic birth).

5. Could you describe any presenting problems you can remember for this client group?

F.U. are you able to tell me approximately how soon after the birth you saw these clients?

6. Could you describe any diagnosis you made for relevant clients?

Relating to $2^{\text {nd }}$ Objective (15 mins):

7. Which therapeutic approaches do you use?

F-U. Can you tell me about techniques from any other approaches you might use? (can give eg. attachment theory and expressive writing from PDA if helpful).

Potential F.U. How would you feel about borrowing from approaches, alongside those you use?

8. Tell me about any specific interventions you remember using with this group.

F-U. Are there any others you can describe?

9. Do you manage these cases in the same way you would manage cases relating to other sources of trauma?

Potential F-U. Tell me what is different.

Relating to $3^{\text {rd }}$ Objective (10 mins) \& Additional:

10. Tell me about the therapeutic outcomes you remember.

Potential F-U. (set session-no. therapists). I'm wondering if you were satisfied with the length of the therapy?

F-U. Talk to me about follow-up.

11. Could you describe any professional difficulties you might have come across in supporting this client group? F-U. What do you think about carrying out further relevant training? (can give examples of EMDR, expressive writing, other approaches).

12. Please feel free to add anything you think might be relevant.

\section{Closing (1 min):}

13. Thanks, Ethical Debriefing Form, reminder to seek support if has caused professional or personal issues to arise.

Figure 1. Interview schedule. 
ingful questions prior to the interview, while also enabling movement around the subject area (Pawar, 2004) and flexibility in response to any new concepts that arose during interviews (Adams \& Lawrence, 2015). Simultaneously, this approach allowed the refocusing of interviewees when they departed from the subject. Open questions enabled participants to give information-rich, full answers (Miller \& Brewer, 2003). Follow-up questions and examples, where appropriate and not leading, helped draw detailed information from participants. Questions reflected the objectives of the research (Roller \& Lavrakas, 2015). A brief reminder of the research subject, rationale and aim were given, before asking 3-5 main questions per objective with follow-up questions available where necessary (Figure 1). Finally, to reduce the impact of limitations caused by the researcher's own understanding of the subject area, the participants were asked to add anything they felt was relevant (Bowling, 2009).

The schedule was reviewed, refined and practiced with peers in order to obtain as much high-quality data as possible. Interviews were intended to last 40-50 mins, giving enough time to attend to the objectives, while giving opportunity for participants to add information. Two interviews over-ran, 4 and 8 minutes, due to the speaking style of the participants and the provision of additional information. The others remained within the 40-50 mins aim. Three interviews took place in person, at the participant's premises, and 3 via Skype due to distance and scheduling difficulties. Each interview was simply analysed prior to the next, determining basic themes and gaining a clear idea of the data that was emerging, enabling a comparison with information already gained (Ando, Cousins, \& Young, 2014).

\section{Data analysis}

Interviews were transcribed before being methodically and carefully analysed to create a narrative detailing the researcher's interpretation of the data, supported with appropriate quotes directly from participant accounts (Smith et al., 2009). There are various methods proposed for performing IPA but it is suggested they all essentially follow the same processes, to produce meaningful interpretations from participant description, and the same principles, a commitment to understanding how participants perceive events with an emphasis on finding meaning from their accounts (Reid et al., 2005). Smith et al. (2009) neatly present the various strategies involved in carrying out IPA, drawn together in a practical, structured process of analysis. It creates opportunity for the researcher to adopt both emic and etic positions throughout the process, essential in IPA (Clarke, 2009; Reid et al., 2005), consistently moving from immersing oneself into the world of the participant and stepping out to attempt to make sense of it. The use of this structured process is outlined below.

The process began with reading and re-reading the first participant's transcript, noting anything that stood out. A three-columned table was created, the participant's account placed in the middle column. Exploratory comments, regarding descriptive, linguistic and conceptual elements, were detailed in the right-hand column. Highlighting remarkable or significant linguistic aspects enabled the consideration of potential connotations and meaning without needing to perform the lengthy process of Jeffersonian style transcribing, which is arguably more suitable for Conversational Analysis (Willig, 2008), where the focus is on the role of language and how the account of an experience is formed rather than how the individual makes sense of that experience (Smith, 2011). Noting evident or abstract concepts began the process of establishing and making sense of patterns of meaning. All the exploratory notes were then considered, the left-hand column used to suggest emerging themes. It was then possible to map how those themes might fit together, identifying connections, recognising sub-ordinate themes and assigning basic titles. These sub-ordinate themes were then put through the detailed process of looking for differences and correlations to establish patterns, using abstraction, polarisation and subsumption, while also noticing the frequency of certain themes or how their functionality might bring them together, super-ordinate themes appearing. It was considered how those super-ordinate themes related to the research aim and objectives and fitting names were allocated, hopefully accurately exemplifying what is at the heart of the participant's experience. Before moving onto the next participant's account, the super-ordinate themes were reviewed in relation to the transcript, identifying the relevant line numbers and keywords, contemplating the honesty of the interpretation and ensuring it reflected what was originally said.

Once this process had been completed for each participant's transcript (using pseudonyms instead of their real names), resultant super-ordinate themes were considered, in parallel, to identify patterns (Table 2).

Those concepts shared across participants and those that were unique, as idiosyncrasies, were noted. A Master Table of Themes was then created for all the participants, displaying supportive statements with an assigned participant pseudonym and line number to locate statements in the original transcriptions. This enabled the production of a detailed analytical account for discussion.

\section{Findings}

The overarching concept, evident across the participants and throughout the course of the interviews, is that women come to therapy with a deeply personal birth story, which they want to tell but have nowhere to tell it, and a sense of being profoundly altered by their experience, as Becky illustrates:

"Actually there's, I think, a sense of alienation, of being alienated from oneself. So, experiencing oneself in ways that are really out-of-kilter with 'who I thought I was'... They often feel that their version, their story... the key story is, you know, 'other mothers, their story isn't like mine', and there's nowhere to talk about what happened." [Becky]

This concept is reflected in the headings and content of 3 ostensible areas for focus, each relating to the therapeutic process and presenting the associated themes drawn from the participants' accounts: i) Hearing the story: discovering the altered-self; ii) Working with the story: enabling redemption of the altered-self; iii) Professional challenges related to the wider story: advocating for the altered-self.

\section{Hearing the Story: discovering the altered-self}

This is the beginning of the therapeutic process, where the therapist is exploring the issues, assessing the client, and determining how therapy might unfold.

"I really try to get a sense of where people are. What's brought them here? Why now? What effect is it having? What do they want out of it? How do they feel?.... how low are they feeling and a risk assessment... And you're sort of guessing a bit as well. You're trying to figure it out. What do I think I could offer?.” [Ruth]

\section{The first hearing: assessing the impact and revealing the altered-self}

In the initial sessions, the majority of therapists take a relevant history and carry out thorough assessments, including risk assess- 
ments, utilising questionnaires and scales such as GAD-7, PHQ-9 and PCL-5, sometimes alongside specifically designed structured interviews. Other therapists like Kate, see assessment tools as a hindrance and use a more unstructured method, "It hampers rather than helps me... it stops me listening because I'm focusing on the tool... and what do they actually tell us anyway?". All of the therapists refer to clients describing typical trauma symptoms, 'flashbacks', 'panic attacks', 'rumination', 'nightmares', 'intrusive images', 'not sleeping', 'not eating'; alongside mood disturbances and negative emotions, 'feeling low', 'very upset', 'really anxious', 'guilt and shame', 'isolation', 'fear', 'terrified', 'vulnerable', 'out of control', 'angry'. They also commonly mention the disclosure of relational issues with babies and partners, 'bonding doesn't feel right', 'couldn't breastfeed', 'over-protective', 'sexual issues', 'partner becoming carer'. Avoidance of multiple triggers is reported, 'her baby' 'other mothers' 'pregnant people', 'babies in prams', 'other birth stories', 'avoidant of having children', 'hospitals'. Several therapists voiced concern at the use of hospitals for debriefing and counselling services, as Sue suggests, "Just going to the hospital can be a massive trigger". There are differing views on use of diagnoses, but the therapists interviewed agreed that clients present with symptoms in common with 'Birth trauma', 'PTSD', 'PTS', 'anxiety', 'depression', 'OCD', 'relational problems', 'adjustment disorders', 'reoccurrence of previous trauma' and 'tokophobia and other associated phobias'.
While some women learn to live in this new reality, the need to address the trauma may still present itself years later, therapists speaking of, ' 5 years', '25 years', '31 years'. Becky suggests trauma may even lay dormant for a generation, "It's a little-known phenomenon that grandparents can become triggered into their own trauma". The timing for accessing help varies enormously and seems largely dependent on how women experience and respond to the symptomatology and the altered-self.

"Well the longest was a woman I saw recently who was $74 \ldots$ then I have people who phone me within 5 days. When they're pregnant again is a very, very common one.... Or many years later, they've got a bit of space in their life.... At that time, they realise they're not quite right and they're not gonna be right." [Kate]

Regardless of the point at which women seek support, clients come with a desire beyond their need to address the intense emotional, physical and intrusive symptoms of trauma. As Ruth explains "A lot of people want to come and tell their story. I wouldn't normally say, 'Tell me your birth story' even, people just do, they absolutely do". Nicola provides a glimpse into the nature of this need, "They want to be heard, that they were under threat, overwhelmed, helpless, out of control. They need to be heard". As Sue explains, the story clients need to tell, and have someone hear, refers not only to the tangibly traumatic elements of the birth but

Table 2. Identifying areas for focus, higher concepts and recurrent themes (Yes/No).

\begin{tabular}{|c|c|c|c|c|c|c|c|}
\hline Super-ordinate themes & Ruth & Kate & Nicola & Sue & Becky & Jackie & Present in $>$ half \\
\hline $\begin{array}{l}\text { Focus/higher concept - Hearing the story: discovering the altered-self } \\
\text { The first hearing: assessing the impact \& determining the issues } \\
\text { (including subthemes of assessment, symptoms, triggers, timeline } \\
\text { for accessing therapy, diagnosis) }\end{array}$ & Y & $\mathrm{Y}$ & $\mathrm{Y}$ & $\mathrm{Y}$ & $\mathrm{Y}$ & $\mathrm{Y}$ & $\mathrm{Y}$ \\
\hline $\begin{array}{l}\text { Loss: expectations, autonomy \& the failed-self (including subthemes } \\
\text { of autonomy, unmet/inaccurate/birth/extreme expectations, failure, } \\
\text { societal acceptance, loss of control) }\end{array}$ & $\mathrm{Y}$ & $\mathrm{Y}$ & $\mathrm{Y}$ & $\mathrm{Y}$ & Y & $\mathrm{Y}$ & $\mathrm{Y}$ \\
\hline $\begin{array}{l}\text { Recognising the potential impact of the preluding-self } \\
\text { (including subthemes of attachment, trauma perception, fearful anticipation, } \\
\text { anxiety \& control) }\end{array}$ & $\mathrm{Y}$ & $\mathrm{Y}$ & $\mathrm{N}$ & $\mathrm{N}$ & $\mathrm{Y}$ & $\mathrm{Y}$ & $\mathrm{Y}$ \\
\hline \multicolumn{8}{|c|}{ Focus/higher concept - Working with the story: enabling redemption of the altered-self } \\
\hline Authentically hearing, validating \& reframing the story & $\mathrm{Y}$ & $\mathrm{Y}$ & $\mathrm{Y}$ & $\mathrm{Y}$ & $\mathrm{Y}$ & $\mathrm{Y}$ & $\mathrm{Y}$ \\
\hline
\end{tabular}

(including subthemes of hearing the story, need to be heard,

validating, working with empathy, challenging interpretation,

reappraising the story, reframing guilt)

Reinstating reasoning (including subthemes of psychoeducation,

normalising the adjusting-self, stabilisation, detaching negative emotions,

'rewind' technique, reclaiming what's lost)

Attaining the requested resolution (including subthemes of emerging

additional issues, trauma first, transference, outcomes

subsequent pregnancy)

Focus/higher concept - Professional challenges relating to the wider story: advocating for the altered-self

Birth trauma as unique: the need for a tailored approach

$\begin{array}{lllllll} & \mathrm{Y} & \mathrm{Y} & \mathrm{Y} & \mathrm{Y} & \mathrm{Y} & \mathrm{N}\end{array}$

$\mathrm{N}$

Y

(including subthemes of the existential aspect of birth trauma,

need for varying approaches, subjective loss of sacred experience,

birth trauma as unique \& subjective, a specialist subject)

Frustrations with unaware professionals \& the NHS (including subthemes of NICE guidelines, frustration at NHS approach, referral, gap in services, lack of understanding, misdiagnosis, professionalism)

The costs and benefits of overlapping roles (including subthemes of positives, negatives, the conflicted-self, overlapping and roles, finding the balance, medical terminology, ongoing relationship) 
the whole experience "They will talk me through their birth story, from start to finish". Becky illuminates this concept, "Their story of the childbirth might even stretch back to the pregnancy... and even may stretch back to how the baby was conceived". For Kate, the stories are so significantly detailed they negate the need for any other assessment, "I assess by listening and that's all I do. I hear their story and that gives me an idea of where I think we can go with it".

These detailed subjective stories culminate in an overwhelming impression that something is, as Becky expresses it, 'out-ofkilter'. She expounds, "What they're saying is, 'This is not me, this is not how I expected to be as a new Mum', so almost a sense of departing from the script". Women initiate therapy with a sense that some unquantifiable aspect of themselves has altered in some way.

"People feel fragile afterwards, they feel that there's something about themselves that's been broken, that they thought was ok and now's been changed, so people feel physically changed, even changed in the sense of self'. [Ruth]

This unsettling of the self often presents as a general questioning, a need to understand the world in which they now find themselves, as Jackie illustrates, "They were left feeling, I suppose, shattered assumptions about themselves, the world and their future.... questions about how they'd been left".

\section{Loss: expectations, autonomy and the failed-self}

To address the presenting issues, therapists 'explore' and 'investigate' the story, determining how the birth was experienced as traumatic. Standard trauma criteria, regarding the perception of oneself or a loved one being exposed to the threat of death or severe injury, were only, briefly, referred to by Jackie, "The emergency bell is pressed and people come running in... 'I thought the baby was gonna die'... The perception of that danger for themselves comes out too". The overwhelming message, regarding what constitutes birth to be experienced as 'traumatic', and communicated by all the therapists interviewed, is encapsulated by Sue:

"It's loss with the birth trauma. Loss of that expected birth, loss of control... there's a lot of sadness and a lot of loss attached to it". [Sue]

Most participants raised the societal 'movement' towards 'natural', 'positive' and 'beautiful' birthing as being a relevant factor. The development of 'unrealistic' and 'idealistic' birth expectations seem to be an unanticipated consequence of a progressive campaign to fully 'prepare' and 'empower women'.

"It's unrealistic expectations... I think that birth culture in this country peddles the myth that as long as you're well prepared and you've done your breathing and you've attended your antenatal classes, you can just sail through it, which sorry is B.S." [Becky].

The reality of the birthing experience can be quite different to what women are expecting. Consequently, as Jackie reflects, "There is a sense of 'This is not how it was supposed to be"'. She, along with Sue and Nicola, explain that this is particularly problematic for those women who have put significant effort into antenatal preparation, often developing detailed birth plans of what they want to happen, assuming, "everything is gonna be wonderful" [Jackie]. Nicola explains, "They look at their books and think, 'oh this is how it is going to happen', and then struggle because it didn't happen the way they expected it to". According to all the therapists interviewed, where expectations are unmet, women are left feeling some form of 'devastation' because what 'should have been' a 'beautiful', 'natural', 'sacred', 'amazing' experience has been 'ruined'.

"(women) are just so phenomenally disappointed and kind of broken by that, how something could be so vastly different from what they would have wanted." [Ruth]

The descent into the unexpected, a shocking transition from the anticipated and well-planned birth, can happen in a moment, Ruth describing how, "it can go from quite nice to utterly chaotic in seconds".

“They've gone from very high expectations to all of a sudden being incredibly, umm, helpless, and massive loss of control, because what they wanted isn't happening and they don't know how to... communicate, so they become helpless, and therefore things are done to them, rather than it being that discussion of risks and benefits and decision making and informed choice." [Sue]

Sue describes a sequence in the traumatic loss of autonomy, which is reflected in the accounts of other participants. The initial loss comes from exposing the illusion that the woman has control over what is happening, as Ruth shares, "part of people's difficult experience is that they lost all agency... at that point, events overwhelmed them". The secondary loss stems from being unable to engage with the care-givers, Sue explaining, "I hear that regularly. 'It would just have been nice if someone had told me what was happening, if someone had held my hand... just letting me know what was going on"'. Nicola expands on the role of communication in the loss of autonomy, describing how women feel unheard, "Not every birth trauma is about traumatic birth... there was nothing traumatic, but nobody listened to them". The final element refers to a perceived shift in the possession of power, from self to others. Nicola illustrates this with an example regarding 'giving consent', "She didn't really consent, all the non-verbal communication was saying, 'You are going to do this'. She hadn't been in control. She hadn't made the choice or understood how to stop it. It was already happening around her". In situations like this, women experience not only a loss of autonomy but an invasion of autonomy, as Ruth illustrates, "what that person did to them...it's about them feeling intruded upon, them not having a voice... feeling invisible, feeling powerless". Participants describe a palpable overall sense of being a victim.

"It's a lack of ability to gain the information they need to remain in control throughout that birth, the feeling that the things that were done without their consent... so the message that I get is, "This almost felt like assault. Things were done to me and I don't know why they were done to me and I don't feel like I had any choice in the matter'." [Sue]

There is a clear juxtaposition here with sexual trauma, Ruth comparing these clients to those who have been raped, "that's an attack on self, and that's about the integrity of the self as well". Kate states it clearly, "It's like rape. It's something that should be sacred and special that's been abused". She later refers to the bewilderment of experiencing birth as traumatic in this way, "They know, at some level, that it shouldn't have been like that and they're confused because, to everyone else on paper, it kind of 
looks normal". This confusion perhaps contributes to the altered sense of self. If, as with sexual trauma, women who experience birth in this way also undergo a shift in their world view, it may be easier for them to blame themselves than to accept they had no control over events. This concept of misplaced self-blame and 'the failed-self', was raised by half the therapists interviewed, Nicola recalling a specific client, "She just couldn't live with the fact that she'd done this thing, when actually it wasn't the thing she had done, it was the thing she'd had done to her" and Kate asserting, "often self-blame is a big, big part of birth-trauma, certainly in my experience... or 'I should have done something differently"'. The general perception of having failed also seems to link back to cultural expectations and promoting normal birth:

"I think there's a lot around about raising the profile of women in birth and positive birthing, which is great, and we do need that... but I think within that there's a danger that we set women up to fail...because as well as giving them all the positive messages about how wonderful it is and how natural it is and how empowering it is, they're not given the plan b, c, d. So, they're doing all of the 'right' things and still it is traumatic." [Sue]

Nicola remembers a particular client who, following 3 natural births, had agreed to an elective caesarean due a medical issue, "Afterwards she felt she had let herself down by agreeing to have the c/s. It wasn't traumatic in any way but she felt she had lost the element of control and so made the wrong decision with it". The consequences of perceiving oneself to have failed in some way, regardless of the cause, seem to be far-reaching, Sue explaining, "Then they question their own competence... they struggle with feelings of guilt and shame... see themselves as a failure as a mother".

\section{Recognising the relevant preluding-self}

All the therapists denote 'pre-existing', 'predisposing' or 'additional underlying' issues as potentially impacting how women experience birth as 'traumatic', and consequently as relevant to the therapeutic process. The weight of emphasis placed on such issues seems largely dependent on the approach of the therapist. Becky, for example, is predominantly a psychodynamic therapist, "I am looking for attachment experiences which, in my model of therapy, may predispose women to being traumatised by certain types of caregiving within the perinatal experience". She expands on that, explaining attachment as a neurobiological factor in trauma, "Where we feel threatened or scared or unsafe, we will look to another human being... if I'm feeling terrified and I look to the midwife and she also looks terrified, that's likely to ratchet up my sense of being terrified". Nicola agrees with the concept of early experiences influencing the traumatic aspect of birth, raising family 'templates' as an area worthy of exploration and stating, "Often there are other things that come into it, outside the birth, particularly relationships with other key female members of the family". Jackie explains how the behaviour of care-givers, during birth, can trigger childhood trauma, recalling a specific client whose labour triggered feelings of worthlessness and a fear of abandonment, "the delivery really reinforced that belief... that was the focus of the therapy, rather than re-experiencing or PTSD ... you know, "I felt worthless, I felt abandoned, I felt that nobody cared for me"”.

"Women who have become self-reliant, where the carer has not been consistent, or in fact has been neglectful; many of these women developed a false self, so that they will look and feel very much in control, very much in command. They may be quite per- fectionistic for example... Where the woman looks to the caregiver, but the care giver doesn't pick-up the cue, the woman goes back into that tried and tested 'right ok, well I'll look after myself', but obviously that isn't possible.” [Becky]

This apparent 'self-reliance', appearing as 'control' and 'perfectionism', is the most frequently mentioned common factor in client histories. While Becky recognises it as an attachment-based issue, other therapists, such as Ruth, explain it as stemming from pre-existing general anxiety, here illustrating how anxiety informs the birth experience, "the desire to control things, to manage that anxiety, then having an experience that they were utterly unable to control, that sort of left them floundering". Jackie notes "Existing anxiety does seem to be a precipitant to trauma", also elucidating how women with anxiety are more likely experience birth as traumatic when events move outside their control:

"They always have control in their lives, they want to do this perfectly. They want the perfect pregnancy, they're gonna have the perfect delivery and they're gonna be the perfect Mum. So yeah, perfectionism and control. These women really fall down". [Jackie]

Becky further addresses the problem of attempting to achieve that perfect birth, "That doesn't allow for unforeseen circumstances or the fact that bodies don't often quite work in the way we want them to". Historical factors, precipitating an attempt to control birth and employ self-reliance, emerge then as an apparent foundation for the described loss of expectation and autonomy, initiating the subjective experience of trauma.

\section{Working with the Story: enabling redemption of the altered-self}

This relates to the middle and end of the therapeutic process, where the therapist works with the client on the presenting issues, employing techniques to fulfil the client request.

\section{Authentically hearing, validating and reframing the story}

For most of the therapists interviewed, the work initiates from hearing the client's birth story, Nicola expressing how clients, "just need the time to talk through it". Ruth describes the therapeutic response to that need, "Part of what I want to do, is to allow them to say it all. Nothing is off the table. Nothing is too terrible", addressing the importance of attending to the story, "Often the reason they can't process it is just that they can't find anyone they can talk to about it". Kate speaks further into the significance of simply listening to client's stories, "I've been treating trauma, before I had any techniques, with listening... I remember being really surprised that people were getting better. I remember thinking, 'I haven't done anything' and it made a massive difference". Jackie reinforces this, describing how she begins work by, "basically, going through their story from their perspective... or get them to write it down, and just doing that can help them to process". Participants referred emotionally to story-telling, Nicola illustrating the seemingly often-arising empathy, "These poor women, they deserve to be heard". This empathy enables the understanding and validation that Ruth recognises was missing in many client's birth experiences and therefore so necessary in this part of the therapeutic process,

"That very personal relational experience at the time has been devastating for them because, umm, there is something about being unseen... a big part of the work is stowing right next to them through that, being able to talk about what that was like, being able 
to understand just how painful it was, what a big thing it was.... So that's a big part of what I do. There's something validating, about them telling me and I can hear what they are saying. I can bear to hear it." [Ruth]

Sue explains the transition from simply hearing the story to appraising the story, using counselling skills to "try and draw things out... do some reflection, to help them to see maybe where they are within that". Jackie describes how she explores the parts of the story clients find most difficult, "looking at the emotions that went round that, the thoughts they had at the time". Most of the participants refer to the presence of problematic distorted birth perceptions, revealed through the stories, which require some form of adjustment.

"So it's just about helping them to look at it because I think sometimes your memory plays tricks on you, doesn't it? And you look back on things and you see it in a very, a very different way". [Sue]

Kate investigates what may be influencing those perceptions, considering "what thinking patterns are affecting this person and how can we shift them". As she intimates, once the problematic perception has been determined, therapists will then attempt to reframe the client's understanding, to bring change. Nicola does this using visualisation, "I tend to do it very very gently, getting them to release negative ideas and beliefs into a balloon... Then we'd spend a whole session on positive things and visualisation and statements". Kate also uses visual imagery to bring change, alongside 'role play', and 'Socratic questioning', explaining, "You ask questions in a certain way, which gets them thinking, 'Oh my gosh', or 'really?' or 'oh yeah', and then they go away and process everything and they think 'oh it's not my fault". Where Kate wants to avoid activating critical thinking, others, such as Sue, will challenge client interpretations directly, stating to them, "“Can we reframe that?' in terms of saying, 'That was not your fault..."'. This misplaced self-blame, featuring heavily in all the accounts, seems to be the main skewed perception therapists work to change. With these clients, as Sue explains, part of the therapeutic process involves, "reframing it in terms of responsibility and control... trying to work through the birth story and put responsibility back where it belongs". Nicola often works with incongruous guilt and shame, remembering the relief of a specific client, "She felt she had... made the wrong decision with it, but she wasn't really involved in making the decision. When she understood that... she just felt better". Mistakenly taking ownership over birth trauma creates enormous problems for women, the reported catharsis achieved by reattributing responsibility reflecting this.

"Just writing that out and putting the responsibilities back had been an amazing eye-opener for her, in terms of understanding what had happened to her... 'Actually, this wasn't me', you know, 'actually it was a catalogue of things that happened'... It's not about apportioning blame as such, like, 'It's the midwife's fault'. It's about reframing and taking the responsibility away from them. Lightens the load." [Sue]

Once those perceptions have been reframed, clients may be asked to tell the story anew, Jackie explains, "We are going through their narrative again... putting in their appraisal, umm, recording those sessions and getting them to listen to them again and again with the reappraisal". Although therapists vary in how they work to reframe perceptions, whether its directly or through the use of reflective counselling, it seems to be an important step in the therapeutic process. As Sue sums-up, "it can be really powerful, really helpful".

\section{Reinstating Reasoning and Control}

Simultaneously, to working with the client's story, therapists describe the need to 'normalise' and 'explain' debilitating traumasymptoms. By all accounts, this begins with psychoeducation, Becky explaining, "This bit is the 'making sense' [bit], trying to make sense of where these symptoms have come from". She goes on to describe how she addresses the difficulty some clients have in understanding what is trauma-related and what is a normal part of the transition to motherhood, "'This is the trauma bit, and this is the bit that might have happened anyway, regardless of the trauma', you know, 'This is the life stage. This is you moving into a new role", hinting at the complications surrounding experiencing trauma in the context of an already life-changing experience. The content of psychoeducation depends on the client's circumstance. For example, as Ruth explains, where the trauma is very recent, "my focus is more on how to calm the emotions, how to soothe themselves... Also, normalising it, 'Of course you feel like this, this is really normal"'. Where symptoms have persisted, Sue explains how she will, "give them a very, kind of, layman's understanding about PTSD”, whereas Ruth provides more detail, here illustrating the purpose of psychoeducation,

"I do share about PTSD and how memories are misprocessed and why it is that they feel like they are re-experiencing it rather than remembering it... and that's empowering for them. It feels like I'm giving them something to say... 'this is something that is gonna happen, it happens to lots of people, you're not going mad, you're just not processing the memories'." [Ruth]

Jackie concurs that psychoeducation is 'empowering', revealing that, "For some women, that is even all they need. You know, the knowledge that they weren't going crazy, they weren't losing the plot... psychoeducation is key to help them understand about their brain processing trauma”. Kate demonstrates how empowerment, via psychoeducation, enables clients to apply reasoning to their birth perceptions and overlaps with reframing their birth stories, "If they're talking about wanting to scream and not being able to vocalise the scream, I might talk about how when we're birthing, you're almost muted... I might sort of bring in an evolutionary argument for them, 'Oh that's why I didn't complain, that's why I didn't object'".

Becky speaks specifically about how she addresses 'symptomatology' associated with trauma, "I will use a lot of neurobiology in explaining to patients you know, what the 'flight, fright, freeze response' is and what that then produces in the mind and in the body". She explains this is particularly significant in the early part of the therapeutic process, to, "really give them back a sense of control". The use of stabilisation and grounding techniques is evident across the accounts, therapists referring to, 'relaxation techniques', 'breathing techniques', 'mindfulness', 'progressive muscle relaxation', 'distraction techniques', 'meditation', 'safe place imagery', Nicola mentioning, 'I use a lot of nature'. Ruth explains how such skills can "help people just to manage". Sue explains how grounding techniques manage the risk of re-traumatisation, "especially when they're doing that birth story, umm, to keep themselves safe and... just to control their anxiety". Becky expounds, "This is key, common-sense, of being able to read the signs in the room. You know, someone is becoming activated or is being drawn back into that cycle... is becoming less able to func- 
tion, more disorganised, then clearly you need to stop what you're doing, go back and stabilise them". Jackie reinforces this, also expressing the importance of making sure clients, "weren't leaving the sessions feeling highly anxious or upset" and ensuring clients can then, "use these skills at home if they were having any re-experiencing symptoms or any anxious times".

Four of the six therapists interviewed use hypnotic and visualisation techniques, "alongside the counselling" [Nicola], to reduce the presence and impact of intense negative emotions. Nicola uses hypnosis, "because it's a very quick at releasing the emotions attached". Sue advocates the use of hypnotic scripts to, "build confidence moving forward". Kate addresses the argument regarding the legitimacy of hypnosis as a psychotherapeutic technique, specifically its use in the NHS, "you kind of think, 'Why are you still saying "No" to hypnosis? Why after 150 years are you still saying we can't use this?'... It bloody well works". She, Sue and Ruth all enthusiastically endorse the Rewind technique, using it routinely and successfully as part of the therapeutic process. Ruth explains it as, "a way of processing the memory by dissociation if you like, where you process it but without the emotional arousal, so you're able to think through the memory but without the emotional system becoming so active it prevents it from being processed properly". Sue sheds light on how this enables the continuation of the therapeutic process, "When we've done that, we're able to look at things more realistically and have that reasoning thought process go on... without the intense emotions attached to it". Conversely, Jackie expresses some concern regarding 'Rewind', "There seems to be a lot of people training in it who have no other psychotherapy experience... if it all goes pearshaped I suppose they don't have the skills to sort of, rectify it or offer anything else". Such 'skills' enable her to confidently manage the use of CBT in vivo exposure, "to take them [clients] back the place of the trauma". Kate declares Rewind to be her 'favourite' intervention for birth trauma, "I reduced my therapy sessions from 12 to 3 with the Rewind technique", here comparing it with the use of CBT exposure techniques, in which she is also trained and practised for many years,

"It was awful and the people I worked with didn't enjoy it... They'd be in a right mess... And the thing was, they would get better but 'no pain, no gain'. Oh, my God it was awful and now, I can, oh it's so nice to have this technique where people shift so quickly and painlessly".

\section{Attaining the requested resolution}

The emergence of additional issues, commented on by all the therapists, hugely influences the length of the therapeutic process. Nicola explains that for some clients it is 'quite obvious' and 'very specific' that the issues relate only to the birth, but for other women, "it can be a little bit more complex". Ruth notes, "There's a sort of difference with what people present with and... what actually comes out as being the thing that really matters to them". She explains how some women will come with birth trauma but 'barely talk about it', other issues taking precedence. Consequently, as Jackie puts it, "sometimes there is more work that is needed". Sue estimates that as many as half her clients will require 'a couple more sessions' on additional issues.

"Some women will come in and that's it. "It's just the birth. Everything after the birth was ok but I can't get that birth out of my head and the impact that that has". For those women, the three sessions is normally enough. So, it's normally if somebody comes in with something else running alongside it or underneath it that we would continue to work together". [Sue]

In this instance, Kate and Sue both strongly advocate dealing with the trauma first and then consider 'what's left-over'. Kate states, "Always go for the trauma first because it's easiest to lift. It's the safest. It's the less complicated".

Nicola sums-up the consensus regarding therapeutic outcomes, "In general, it tends to be that they do have positive experiences... that they get to where they want to be. They just feel better. They've put it into perspective and feel it's a lot easier." All the therapists report 'positive' and 'good' outcomes, the length of therapy seemingly dependant on the approach of the therapist and the presence of additional issues, but therapeutic requests commonly being met within $3-8$ sessions. Those using the Rewind technique report the quickest success, as Sue explains, "[After] those 3 sessions, they are in such an improved position and they don't feel that they need anything else", Kate emphasising the swift nature of this technique, "If I'm pushing into 8 sessions, there something wrong". Jackie, a pure CBT therapist, expects the work to take up to 20 sessions but notes, "I probably wouldn't want to be doing more than that", elucidating birth trauma is normally treated quicker than other issues. This may be partly explained by a point mentioned across participant accounts: one of the most common times women will access support is during subsequent pregnancies, half of the therapists going onto outline how this introduces an urgency to the therapeutic process. Nicola illustrates, "With the pregnant ladies, because often they're up against it, what they want is for the fear to go. They don't want to spend too long talking it through. They often come quite late. Well into their 30 weeks, yeah saying, 'I'm terrified. I just can't shake it off'". Jackie indicates how therapy may be driven by another urgency, that of a new mother, "At that stage, people want to get on and have a life. They want to be with baby. They want to just do the stuff they want to do and move on".

The positive outcomes associated with this client group may be significantly influenced by the client's apparent commitment to therapy. Kate, Sue and Becky all stress they have not had a single drop-out, Jackie also expressing, "In my experience, the women I treat tend to keep going with it", and Ruth recalling and interpreting, "We don't particularly have high drop-out rates compared to other things... Yeah, people who come really come and want to come." Becky indicates this success is not solely due to client commitment but also relies on the therapist's understanding, emphasising the significance of the therapeutic relationship and potential for transference, "Sometimes they can be very angry with you. They can want to test you. You're another health professional that may or may not let them down... So as long as we are prepared to work with those parts, I think therapeutic outcomes can almost always be satisfactory". Regardless of the overall reasons for the speed at which positive outcomes are reached, the desire to adjust and continue onwards is apparently almost always met in some liveable way.

"Most commonly, people get to the point where they can stop carrying it round all the time and they feel that they can stop looking back and start looking forward... It's sort of obvious when they're done. At the end of it, it's like that quote about neurosis to everyday misery. People just sort of feel sad then, they're just left with this wistful sadness about it like, 'Yeah it was crap and I'll never not feel sad about it but it's alright now'." [Ruth] 


\section{Professional Challenges and the Wider Story: advocat- ing for the altered-self}

This part concerns any voiced professional challenge, related to or arising throughout the therapeutic process.

\section{Birth trauma as unique: the need for a tailored approach}

All but one of the participants voiced how 'different', 'specific' or 'totally unique' birth trauma is, in relation to other forms of trauma, but found it challenging to pinpoint exactly how it is different, Sue's ambiguous comment demonstrates the general perplexity surrounding this concept, "I think, I don't know, it just, it just feels very different". Other participants agreed, but tried to find an answer as to why this may be, Ruth providing one possible explanation,

"There is also something that is existentially important about birth... that can't be described as anything else because life is different from anything else. This was supposed to be something that was the beginning of life and something beautiful and amazing and yet it's become tainted with this, these horrible things".

Kate also perceived the interruption of the expected existential experience of birth as being a possible reason for the uniqueness of birth trauma, "It's not like having your toe put into an escalator in Primark. It's not like being in a car accident, it's different... It's something that should be sacred and special that's been abused". Ruth expounds, "If you have an accident, or you get robbed, or you have an earthquake, yes, that's happened to you but it's not interwoven with one of the most important events of your life". There is a general recognition that, unlike most other traumas, these women are already undergoing a lifer-altering experience when trauma occurs, Becky explaining, "They're not just dealing with trauma, amidst the trauma, they're also struggling to become a mother", Ruth considering, "How do you put having a baby within that trauma?". Consequently, the management of birth trauma differs from the management of other traumas, Becky simply noting, "It's a therapeutic model that's quite different to how I would work with others".

"It's a very specific thing that you can't really compare to anything else.... In that, it's ongoing, in that there's the baby all the time. I feel it is such a different subject that I do actually deal with it in a different way". [Nicola]

For Sue, the Rewind technique is particularly useful in Birth Trauma, detaching the intense emotions evoked, "which I think doesn't apply necessarily so much with some of the other PTSDs because they're not about that intense emotion, it is more about shock". For Ruth, the difference revolves around the story-telling aspect, "I think in the telling of the birth story, there's something about it that just is more, relevant than the telling of, I don't know, I suppose we don't have a 'my traumatic accident story'... there is something about being able to tell that tale, give meaning to that most significant event that is, that is more than just trauma". Whereas Becky explains why, for her, the use of stabilisation is more important in birth trauma than other trauma, "because there is a little human being who is going to be exposed to that person as and when she leaves the session".

Part of the challenge is not only understanding birth trauma as being unique but understanding how it is unique to the subjective interpretation of that client and how predisposing issues and coping mechanisms may interact with the trauma, as Ruth states,
"People are very different actually. They are really different and it's so personal how birth trauma has then affected them and what the significance is". All but one of the participants meet this challenge by integrating various combinations of Cognitive Behavioural Therapy, Psychodynamic Therapy, CompassionFocused Therapy, Person-Centred Therapy, Human Givens, Neurolinguistic Programming, Emotional Freedom Technique, Hypnosis, Eye-Movement Desensitisation Reprocessing, MindBody Work and Mindfulness. Becky explains, "You tailor the therapy to the patient and you know, whatever works, works and it will be tailored for each person I see". Kate enjoys the ability to integrate different approaches, "You decide suddenly with somebody, 'this might work for you', and you just do it". Nicola explains why she sees an integrational approach as being necessary,

"Because every client is different, sometimes you might have a client and think, 'oh this is just not them at all'... I think, as a therapist, you need a full tool bag, so you can delve in and find a different thing, because for somebody else that might not have been the thing that works. It's important to have quite a wide range." [Nicola]

\section{Frustrations with unaware professionals and the NHS}

A regularly voiced challenge relates to attempting to work with the multi-professional team. All the participants explained how their private practice clients are all 'self-referrals' who find them 'online', 'on the internet', 'google searching', or 'through organisations' or via 'recommendations' and 'word of mouth'. Nicola illustrates the challenge, referred to by all the participants, facing private practitioners and women who want to access a choice of specialist therapy via their General Practitioner (GP), "The community midwives, the health visitors, the consultants and GPs could at least be sharing that information but there's this block from the NHS. They don't want to recommend private businesses and it's such a shame because there's no sharing of information. Then there's just this gap". She explains that this 'gap' means some women do not have access to any counselling, "turned away by the NHS because it's seen as a specialised issue, so they feel that they can't help them". The 'gap' in services is also addressed by Ruth and Jackie, who explain that where specialist perinatal services do exist, women are often only able to access this care for a short period, Jackie referring to, "rules in the NHS as to how long after the birth I can see them because they'll want me to stay within the perinatal period. Although, you know, trauma often doesn't show itself within the perinatal period".

Even if referrals were forthcoming, therapists describe an apparent lack of knowledge that may hinder that process, Becky here detailing how women's concerns are dismissed by unaware GPs and midwives, "A lot of women come to tell me that they did go to the GP but were told, 'Don't be silly' or they did go to the midwife but were told, 'Oh that happens to everybody"'. Half the participants raised concerns regarding the 'misdiagnosis' of 'postnatal depression' instead of birth trauma, Sue voicing concerns regarding basic care management, "Training for recognition of the fact that actually this isn't postnatal depression it's something else, I think is really important. Lots of the ladies have had an initial diagnosis of postnatal depression, and actually some of them have even been medicated for this". Further to this, the training and knowledge of general trauma therapists was raised, by Kate and Becky, as being inadequate for the specialist subject of birth trauma, Kate recalling, "I've spoken to psychologists who do birth trauma work, and they don't understand that it isn't supposed to be a medical process, it isn't supposed to be scary, it isn't supposed to 
be traumatically painful", Becky reinforcing, "There's a lot of people out there who are trauma experts, who many women I see have seen before they come to me, but they're not perinatal experts and I think that is a very important distinction". She is adamant that more training is required to consider the particularities of birth trauma and the significance of the presence of the baby,

"A lot of the birth trauma training that's out there, you know for therapists like us, is, 'This is trauma. This is flight, fright, freeze'. It doesn't actually address any of the things I've talked about... My fellow trauma experts do not think about the baby at home or the baby in the room, because the babies are also affected by this." [Becky]

All but one of the participants recognise the challenge in finding professional guidelines which are applicable to their approach, voicing concerns regarding NICE guidelines on birth trauma.

"I think the NICE guidelines miss a few tricks really... there's an issue with the way CBT is more researchable and that unfortunately makes it weighted, and the NICE guidelines weighted towards it and I don't believe that. People come and commonly say they've had CBT and find it useful but they want something more than that". [Ruth]

Nicola agrees, describing the NHS using CBT 'like a blanket', explaining the NICE guidelines disqualify those practitioners who offer something other than CBT and exclude women who do not respond to CBT therapy, "I've had a number of clients over the years who say, 'I've had CBT through the NHS but I don't feel any better' or, 'I got worse'... It doesn't fix everybody”. Sue believes, "People who work in the NHS are kind of bound by the NICE guidelines... and I think it's limiting". She reinforces concerns regarding a lack of choice in available therapeutic approaches in the NHS, stating, "Many women have gone through trauma-based CBT and say it hasn't worked for them". Kate was very clear about her thoughts on using the NICE guidelines, "Oh God, I wouldn't dream of it. I read them once, and just thought, 'Oh my God, no'. Too much pathologizing". As a former NHS psychologist, she speaks from experience regarding her frustration with the apparent unwillingness to consider other approaches and techniques, "I think it's interesting how the NHS has a wonderful ability to avoid what works". In contrast, Jackie, as a pure CBT therapist, is satisfied with the NICE guidelines, although she acknowledges the benefits of including other approaches, "Compassion-focused techniques would be useful too". Becky regards NICE guidelines as 'helpful', but believes, "You cannot protocolise this work", believing guidelines must take into account, "interventions at different stages of pregnancy and post birth", speaking specifically about, 'the presence of the baby'. For her, a veteran perinatal psychologist in the NHS, the emphasis on CBT became too much,

"I have a real, eugh, annoyance with CBT. It's just like a big bloody roll of moss that just sticks everything on it... there's nothing but CBT, that's all they offer now. Until I left, 2 years ago, perinatal patients were being offered exactly the same as run-of-themill patients without any focus on how these treatments need to be particular to them. So that's why I left and now I'm full time in private practice." [Becky]

\section{The costs and benefits of overlapping roles, knowledge and experience}

The majority of participants mentioned how obstetric experi- ence, either as a midwife or doula, informs and challenges their practice. Such experience and knowledge is generally viewed positively. Kate explains it adds 'a different layer' to therapy, recognising that, unlike her general trauma cases, she is able to, 'bring my understanding to the table'.

"As a midwife, and having that knowledge of you know, what actually goes on in labour and delivery, has been really beneficial... I wonder if a therapist who hadn't ever been at a delivery or doesn't understand the medical system, would be able to do that as well”. [Jackie]

Nicola agrees that a background in midwifery allows a level of understanding that other therapists may be lacking, "I'm not saying there aren't some brilliant therapists out there, who have done all the extra reading... but I think, some people would just not understand". Ruth further clarifies, "I know exactly what it's like in those rooms, what it can feel like... so I feel like I can really empathise and imagine what their experience was and get a real feel for it". For Nicola, it goes beyond enabling congruent empathy, as she brings her understanding of the clinical aspects of a case into the therapy room,

"I had one lady saying, 'I was bleeding but they kept going on about me going to the toilet and I didn't want to get out bed because I was bleeding so much', and I explained obstetrically why it's important to wee, and she said, 'Well I wish they'd just told me that, it makes so much sense'. Sometimes that fear is really easily dealt with if you give them that little bit of clinical information... It's another form of education really."

As a parallel, Sue, who does not have an obstetric background, expresses she finds it challenging when she does not understand the, "medical terminology and things that have happened to women", disclosing she sometimes has to, "go away and google what they have told me has happened" and believing more knowledge might aid her confidence. Jackie acknowledged that clinical knowledge is not essential because, “that wasn't their experience of it. You know, being able to inform some of their ideas and perceptions from the notes was, was useful for some women but for others, it wouldn't have made any difference really because it's what they believed at the time", Nicola agreeing, "Sometimes it can be helpful, but I have to weigh it up carefully" adding, "and I don't offer opinions", with a fervour that suggested a struggle within. She later disclosed, "There have been times I've wanted to say, 'Really? They did what?'. Yes. That does happen and it is very hard but it's about sticking with how they feel". This is made more complicated where women desire the therapist's informed opinion. As Jackie illustrates, "I would have to explain, 'I can answer about standard procedure...but I wouldn't be able to give detailed answers you might want"'. Nicola has experienced this pressure from clients, to give an opinion, to the degree that she deems it necessary to make a disclaimer, "I always say, 'I can't give my professional opinion on your birth, that's not why I am here. I'm here to talk about why you feel and how you feel and ultimately move forward with things"'. In addition, Jackie reflects on the challenge of personally knowing the people involved in a woman's care and indicates a potential challenge in avoiding defensive practice,

"Often the women carry an amount of blame so as a midwife I hear things about colleagues, which can be quite difficult... and I'll think, I'll know that person is really kind and empathic...I think it's really important to go with the woman, that if she perceived her 
care was bad, it was bad, and not to buy into this defensive way. I'm very mindful of not jumping in to defend people. It's not my, not my role or my job". [Jackie]

For Ruth, the challenge revolves around the conflict in realistically preparing women for subsequent births, as she considers how a woman may influence her birth experience, "It's quite an ask to be able to take control of your birth experience... How do you take control of the things that you couldn't have control over?". She expresses a struggle in the desire to help women, "to speak up, to get what they want, but also know that they can't always get what they want". She struggles to determine the nature of the hardship her experiences on delivery ward have created for her as a therapist, concluding.

"Maybe this is the thing that is hard for me, because I know that a lot of what happens in obstetrics is horrible, and I know that. It's like sending people into the lion's den, because actually a lot of the way it's done is not, not ok, so that's a difficult thing". [Ruth]

\section{Discussion}

\section{Hearing the story: discovering the altered-self}

Findings agree with the symptoms and diagnoses described in current literature, adding 'reoccurrence of previous trauma' and 'adjustment disorders' and emphasising the briefly mentioned altered sense of self (Beck, 2009). Hearing the story, as part of the assessment, is not apparent in current literature but firmly advocated by the findings. The data supports existing explanations regarding variations in prevalence of birth trauma, generally understood to be caused by the differing perceptions regarding a birth that is either clinically traumatic, or meets trauma criteria, and a birth that appears to be 'normal' but that a woman has perceived as traumatic (Ayers et al., 2008; Briddon et al., 2015, Blainey \& Slade, 2015). Here, the emphasis is on the latter, only briefly addressing the criteria-based understanding of trauma. This complements the work of DeGroot and Vic (2017), who pin-pointed failed birth plans as causing a sense of failure and loss. The findings build on this, revealing it is not only the loss of specific birth plans but loss of general expectations, and autonomy, which lead to a traumatic birth perception. The significance placed on the loss of autonomy is supported by the work of Furuta et al., (2016), who note that disempowerment in birth challenges the understanding of the self. Findings indicate this issue often relates to poor communication and negative actions of health professionals, examples giving context to the similar findings of Beck (2009).

A woman's experience of her clinically-successful birth as 'traumatic' may be influenced by pre-existing factors. Existing literature suggests insecure attachment-styles may increase the possibility of birth trauma due to poor coping mechanisms and issues around social perceptions (Slade \& Milby, 2017). Adding further insight, findings demonstrate how certain styles of care-giving in labour can trigger attachment-related trauma. The research found that pre-existing anxiety with associated coping mechanisms around control may also be a factor in birth trauma, likely due to the removal of that coping mechanism at a time when anxiety is often increased.

\section{Working with the story: enabling redemption of the altered-self}

Existing literature promotes the use of numerous techniques from a variety of approaches, supported by the research findings: psychoeducation, mindfulness, relaxation, acceptance of events, story-telling, empathy, validation, the Rewind Technique, therapeutic writing, EFT, EMDR and other mind-body interventions (Barratt, 2010; Baxter et al., 2014; Beck \& Driscoll, 2006; Briddon et al., 2015; Bromley et al., 2017; Gamble \& Creedy, 2004; Gamble et al., 2004; Grigg, 2005; Highsmith, 2016; King, 2015; Kleimann, 2017; Lange et al., 2000; McKenzie-McHarg, 2004; Mayer, 2015; Peeler et al., 2013; Pennebaker \& Chung, 2007; Wells \& Colbear, 2012). The findings place significance on spoken story-telling, rather than the written-form more commonly commented on in literature (Peeler et al., 2013; Pennebaker \& Chung, 2007; Van Emmerick et al., 2008), emphasising the benefits of using empathy alongside it. Existing studies highlight the need for practitioners to be capable of employing stabilisation and grounding techniques (Duckworth \& Follette, 2012; Fisher, 2011), which the findings endorse and add to, raising the presence of the baby and the client's need to function as a mother as issues of note. Empirical data supports CBT exposure-based interventions (Ehlers, Clark, Hackmann, McManus, \& Fennell, 2005; Gamble et al., 2004; NICE, 2014; Schnur et al., 2007) but the findings generally point away from CBT 'reliving' exposure techniques, supporting the use of the gentlest forms of exposure, through story-telling and where dissociation from the memory is created using hypnotic techniques.

Although existing research suggests the use of CBT techniques to enable cognitive understanding and reframe perceptions (Ehlers et al., 2005; Speier, 2017), other than psychoeducation, it does not concretely address the 'how' or 'what' in relation to birth trauma. The findings of the research paint a more detailed picture of 'reframing', including other approaches and providing practical examples, such as: directly challenging perspectives, Socratic questioning, visualisation, role-play, and various techniques to remove misplaced self-blame. The Rewind technique is enthusiastically endorsed, reinforcing existing literature (Guy \& Guy, 2009; Lovell \& Richards, 1995; Simpson \& Dryden, 2011; Slater, 2015) but the contrasting voice raises concerns regarding practitioner proficiency. Existing studies do not seem to address the use of visualisation techniques, which findings suggest may assist with stabilisation and the removal of negative emotions.

\section{Professional challenges and the wider story: advocating for the altered-self}

The concept of birth trauma being completely unique within trauma therapy, the distinct difference stemming from women already being in the midst of a life-changing existential experience when the trauma occurs, appears to be previously unreported. This potentially provides an answer to questions regarding the effectiveness of standard CBT interventions (Blainey \& Slade, 2015; Cunen et al., 2014), focusing instead on working with loss and story-telling, and agrees with the promotion of exploring other options (Fenech \& Thompson, 2014; Peeler et al., 2013). Literature advocating the integration of approaches as a positive alternative to using the recommended CBT (Ayers, 2014; Baxter et al., 2014; Lapp et al., 2010) is reinforced, participants integrating CBT, PDA, PCA, HGA, NLP, Hypnosis, Mind-Body Psychology and Mindfulness. The findings illustrate existing concerns regarding the elevation of CBT over other approaches in the NICE guidelines and the NHS (Clark, 2011; Rachman \& Wilson, 2008; Scott, 2010), painting a more detailed picture of the pressure and limita- 
tions placed on NHS practitioners, the exclusion of non-CBT therapists from professional guidelines, and the absence of options for clients.

Findings give context to concerns regarding a gap in available NHS services (NCT, 2015; Scott, 2010), describing how women are offered limited options or turned away, suggesting a lack of willingness to endorse private practitioners exacerbates the problem. This indicates that the DOH-plans to provide specialist services $(\mathrm{DOH}, 2013)$ are not yet in place or are inadequate. The research agrees with DeGroot and Vic's (2017) findings, that deficient understanding of frontline healthcare professionals leads to misdiagnosis, additionally describing how some women's concerns are dismissed entirely. The expressed need, here, for better training to comprehend and recognise birth trauma, complements the work of those who have developed and advocate the use of screening tools (Beck, 2009; Geller \& Stasko, 2017; Speier, 2017; White et al., 2006; Zimmerman, 2013) and agrees with literature calling for more resources and training for postnatal PTSD (Ayers et al., 2008; Fenech \& Thomson, 2014). In addition, findings champion the recruitment of birth trauma specialists. Finally, it is interesting to note that while challenges regarding the overlapping of professional roles in psychology are addressed in literature (Blumenthal \& Lavender, 1997; Littrell \& Ashford, 1995; Schank \& Skovholt, 1997), there are no apparent studies considering the dual roles of birth-professionals and psychotherapists, clearly outlined in the findings as an area for potential conflict, both on a personal and professional level.

\section{Evaluation}

Participants passionately outlined how important birth trauma is as a subject for research, thus endorsing this study (Guest et al., 2012). Similarities with existing research reinforce and illuminate what others have presented (Smith et al., 2009; Giannouli \& Stoyanova, 2018) while inconsistencies and additions extend the current knowledge, adding to the platform for further research (Cresswell, 2007) and conceivably informing the practice of therapists (Mason, 2017). Purposively sampling participants who draw from a varied experience adds credibility to related findings (Teddie \& Tashakkori, 2009). Problems regarding a lack of understanding amongst professionals in the field ratify the decision to focus on psychotherapists' experience. As a note of caution, this research takes in to account the self-reported experiences of only 6 therapists, 5 of whom are integrational in their approach. It may be worthwhile conducting larger studies, considering the therapeutic process from a wide variety of approaches (Krahn \& Putnam, 2008). This small sample does not change the meaning and significance of the participants' accounts (Thomson \& Downe, 2010), IPA providing an ideal platform to carefully explore, interpret and give meaning to psychotherapists' interpretations regarding experiences (Cresswell, 2007; Forrester, 2010; Smith et al., 2009) of the therapeutic process relating to birth trauma, apparently unexplored in previous research.

It could be argued that the weight given to the challenges associated with the therapeutic process did not reflect the research objectives. However, the fervour and consistency with which the presented challenges were voiced deemed them to be a significant part of the participants' experience, making them relevant to the overall research aim and integral for accurate representation of the collaborative voice of the participants (Smith et al., 2009). In contrast, there were themes not included in the findings, considered as being mentioned by too few participants to truthfully represent the data (Finlay, 2011). Concerns regarding 'debriefing' did not shed new light on a subject that is already widely documented in exist- ing research and so were not included (Porter \& Cohen, 2013). There were interesting findings relating to actions of health professionals influencing the occurrence or prevention of birth trauma, but they did not relate to the research objectives and thus deemed irrelevant to this study (Denicolo, 2004).

The authenticity of findings largely relies on the very human aspects of the researcher to be capable, scrupulous and innovative without being superfluous or sensationalist (Merriam, 1995). This is an unquantifiable factor for the reader, who must trust the researcher to give credence to any meanings attributed to the participants' accounts (Harris et al., 2012). Steps were taken to deserve this trust. For example, being an integrative therapist could create a bias towards integrational approaches but being aware of that potential increased vigilance in staying true to the original data (Newton, Rothlingova, Gutteridge, LeMarchand, \& Raphael, 2012), prompting a further thorough review of the original transcripts to verify findings (Smith et al., 2009). The use of a supervisor will also have guarded against potential problems (McLeod, 2013). Really, the veracity of the results is entirely dependent on the ability of the researcher to interpret the data effectively (Giannoulis \& Giannouli, 2020; Cronin-Davis, Butler, \& Mayers, 2009). Immersing oneself in the material (Shinebourne, 2011), alongside the use of the carefully developed and proven structured analytical approach by Smith et al. (2009), will have increased the likelihood of discovering valid findings for this novice researcher.

\section{Implications for Further Studies and Current Practice}

Techniques around spoken story-telling were heralded as highly effective, it may be helpful to consider why and how this tool can be used successfully. The purported success of Rewind deems further research to be appropriate, although empirical evidence may be difficult to produce therefore qualitative studies perhaps more suitable (Giannouli et al., 2019; Neuman, 2011; Watzlawik \& Born, 2007). It may be worth exploring if those providing the technique are appropriately equipped and qualified to adequately do so. This concept also relates to the wider health care profession, specifically concerning misdiagnosis. Findings advocate training, to identify birth trauma, agreeing with the call for the use of screening tools postnatally (Beck, 2009; Geller \& Stasko, 2017; Speier, 2017; White et al., 2006; Zimmerman, 2013). The unique nature of birth trauma alongside concerns regarding the advised sole use of CBT as per general trauma (Ehlers \& Clark, 2000; NICE, 2014), suggest the development of separate guidelines for birth trauma may be appropriate, including the use of spoken storytelling, the consideration of 'loss', and the relevance of the presence of the baby. An exploration of alternative models would be helpful in addressing the unique aspects of birth trauma, which in themselves require further research and definition, and for those working outside of CBT, as well as clients who do not want CBT. Qualitative research on the impact of overlapping roles, both on the professional and for the client, would be sensible. The arising issues and findings may inform and benefit professionals when moving from one field to another or taking on dual roles.

Phenomenological research findings can positively impact current practice (Patton, 1991), here for psychotherapists and potentially the multi-professional team. Appropriate dissemination is therefore vital (Reeves, 2014; Scullion, 2002), especially in interdisciplinary journals in order to be able to reach a variety of readers who may cite the findings as rationale for further research (Giannouli \& Syrmos, 2019; McBride, 2016). Secondly, the intention is to present relevant findings, in person, to focused target groups (Reeves, 2014). For example, contact has already been made with 2 universities, running midwifery programmes, regard- 
ing the presentation of relevant findings to support their existing syllabus. The hope is to expand that presentation tour, geographically and to other disciplines (Scullion, 2002). Psychotherapistcounsellor CPD training opportunities are another outlet and communications, regarding a collaboration, have begun with an organisation who run 'Rewind' birth trauma workshops.

\section{Research strengths and limitations}

Although this is the first study to investigate in a qualitative way the experience of psychotherapists working with birth trauma, the present study has some limitations. Some interviews were conducted face to face whether others took place online due to practical reasons explained in the methods section. Given that there are no reported differences so far regarding qualitative interviews online and face-to-face, this could be a point of little influence on the results. In addition to that, the sample size was small which may limit the generalizability of the study, but as we have reported following the qualitative paradigm in depth investigation was sought, thus rendering the generalizability element a point for discussion in quantitative methodologies (Stoyanova, Giannouli \& Gergov, 2017).

\section{Conclusions}

This phenomenological study investigated the unexplored experience of psychotherapists working with women subsequent to birth trauma, centring on the therapeutic process. Interpretive Phenomenological Analysis of 6 semi-structured interviews with psychotherapists, who use a variety of approaches and work privately and within NHS, revealed 3 ostensible areas of focus: i) Hearing the story: discovering the altered-self, ii) Working with the story: enabling redemption of the altered-self, and iii) Professional challenges and the wider story: advocating for the altered-self. The findings consistently show that birth trauma leads to an altered sense of self, symptoms commonly stemming from a sense of loss regarding the birth experience and autonomy in labour. Experiencing trauma during the existential experience of birth requires a distinctly different approach than other trauma. This appears to be intertwined with women's need to tell their story in detail, to be heard and validated. Working with this story, to reframe, accept or redeem it, seems to be the focus of the therapeutic process, regardless of the approach, with significance also placed on psychoeducation, stabilisation, detachment of negative emotions and consideration of pre-existing attachment styles and anxiety issues. With reportedly comparatively successful outcomes, all but one of the therapists integrate approaches and voice frustration at a purported gap in available NHS services, national guidelines focusing solely on CBT and many front-line professionals lacking the necessary knowledge and understanding to offer appropriate care. Findings largely support existing research, but the previously under-represented voice of psychotherapists provides insight regarding the therapeutic process for birth trauma.

\section{References}

Abdollahpour, S., Khosravi, A. \& Bolbolhaghighi, N. (2016). The effect of the magical hour on post-traumatic stress disorder (PTSD) in traumatic childbirth: a clinical trial' Journal of Reproductive and Infant Psychology, 34(4), 403-412.
Adams, K. A. \& Lawrence, E. K. (2015). Research methods, statistics, and applications. London: SAGE.

Alcorn, K. L., O'Donovan, A., Patrick, J. C., Creedy, D., \& Devilly, G. J. (2010). A prospective longitudinal study of the prevalence of post-traumatic stress disorder resulting from childbirth events. Psychological Medicine, 40(11), 1849-1859.

Alder, J., Stadlmyar, W., Tschudin, S. \& Bitzer, J. (2006). Posttraumatic symptoms after childbirth: what should we offer? Journal of Psychosomatic Obstetrics and Gynecology, 27(2), 107-112.

American Psychiatric Association (2013). Diagnostic and statistical manual of mental disorders, $5^{\text {th }}$ ed. Arlington: American Psychiatric Association.

Ammerman, R. T., Putnam, F. W., Chard, K. M., Stevens, J. \& Van Ginkel, J. B. (2012). PTSD in depressed mothers in home visitation. Psychological Trauma: Theory, Research, Practice and Policy', 4(2), 186-195.

Ando, H., Cousins, R. \& Young, C. (2014). Achieving saturation in thematic analysis: development and refinement of a codebook. Comprehensive Psychology, 3(4), 2165-2228.

Ayers, S. (2014). Fear of childbirth, postnatal post-traumatic stress disorder and midwifery care. Midwifery, 30(2), 145-148.

Ayers, S. \& Delicate, A. (2016). Recognising and acting on perinatal mental health. Perspective, 32, 27-38.

Ayers, S., Joseph, S., McKenzie-McHarg, K., Slade, P., \& Wijma, K. (2008). Post-traumatic stress disorder following childbirth: current issues and recommendations for future research. Journal of Psychosomatic Obstetrics and Gynecology, 29(4), 240-250.

Barratt, B. B. (2010). The emergence of somatic psychology and bodymind therapy. London: Palgrave MacMillan.

Baxter, J. D., McCourt, C., \& Jarrett, P. M. (2014). What is current practice in offering debriefing services to postpartum women and what are the perceptions of women in accessing these services: A critical review of the literature. Midwifery, 30(2), 194219.

Beck, C. T. (2006). Pentadic cartography: mapping birth trauma narratives. Qualitative Health Research, 16(4), 453-466.

Beck, C. T. (2009). Birth trauma and its sequalae. Journal of Trauma and Dissociation, 2(10), 189-203.

Beck, C. T., \& Dozois, D. J. (2011). Cognitive therapy: current status and future directions. Annual review of medicine, 62(2011), 397-409.

Beck, C. T., Storrs, C. T. \& Watson, S. (2016). Posttraumatic growth after birth trauma: 'I was broken, now I am unbreakable. The American Journal of Maternal/Child Nursing, 41(5), 264-271.

Beck, C.T. \& Driscoll, J. (2006) Postpartum mood and anxiety disorders: a clinician's guide. Boston: Jones \& Bartlett Learning.

Bernard, H. R. \& Ryan, G. W. (2010). Analysing qualitative data. Systematic approaches. London: SAGE.

Birth Trauma Association [BTA] (2017). Maternal suicide rate fails to fall - BTA calls for better mental health support. BTA. [Online] Available from: http://www.birthtraumaassociation.org.uk/media-information/press-releases/33-maternal-suicide-rate-fails-to-fall-btacalls-for-better-mental-health-support. Accessed $3^{\text {rd }}$ Sept 2017.

Blainey, S. H. \& Slade, P. (2015). Exploring the process of writing about and sharing traumatic birth experiences online. British Journal of Health Psychology, 20(2), 243-260.

Blumenthal, S. \& Lavender, T. (1997). The role of clinical psychologists in community mental health teams. Clinical Psychology and Psychotherapy: An International Journal of Theory and 
Practice, 4(3), 192-200.

Boorman, R. J., Devilly, G. J., Gamble, J., Creedy, D. K. \& Fenwick, J. (2014). Childbirth and criteria for traumatic events. Midwifery, 30(2), 255-261.

Boots Family Trust (2013) Perinatal mental health: experiences of women and health professionals. London: Alliance Boots Family Trust.

Bowling, A. (2009). Research methods in health: investigating health and health services, $4^{\text {th }}$ ed. Maidenhead: Open University Press.

Briddon, E., Isaac, C. \& Slade, P. (2015). The association between involuntary memory and emotional adjustment after childbirth. British Journal of Health Psychology, 20(4), 889-903.

British Psychological Society [BPS] Division of Clinical Psychology (2016). Perinatal service provision: the role of clinical psychology. Briefing paper no. 8 update. Leicester: BPS.

Bromley, P., Hollins Martin, A. J. \& Patterson, J. (2017). Posttraumatic stress disorder post childbirth versus postnatal depression: a guide for midwives. British Journal of Midwifery, 25(8), 484-490.

Clark, D. M. (2011). Implementing NICE guidelines for the psychological treatment of depression and anxiety disorders: the IAPT experience. International Review of Psychiatry, 23(4), 318-327.

Cresswell, J. W. (2007). Qualitative inquiry. CA: Sage.

Cronin-Davis, J., Butler, A. \& Mayers, C. A. (2009). Occupational therapy and interpretative phenomenological analysis: comparable research companions? British Journal of Occupational Therapy, 72(8), 332-338.

Cunen, N. B., McNeill, J. \& Murray, K. (2014). A systematic review of midwife-led interventions to address postpartum post-traumatic stress. Midwifery, 30(2), 170-184.

Czarnocka, J. \& Slade, P. (2000). Prevalence and predictors of post $\square$ traumatic stress symptoms following childbirth’ British Journal of Clinical Psychology, 39(1), 35-51.

DeGroot, J., M. \& Vic, T. A. (2017). Disenfranchised grief following a traumatic birth. Journal of Loss and Trauma, 22(4), 346365 .

Denicolo, P. (2004). Doctoral supervision of colleagues: peeling off the veneer of satisfaction and competence. Studies in Higher Education, 29(6), 693-707.

Department of Health [DOH] (2007). Improving access to psychological therapies: specification for the commissioner-led pathfinder programme. London: Department of Health.

Dikmen-Yildiz, P., Ayers, S \& Phillips, L. (2017). Factors associated with post-traumatic stress symptoms (PTSS) 4-6 weeks and 6 months after birth: A longitudinal population-based study. Journal of Affective Disorders, 221(2017), 238-245.

DOH (2013). Boost in specialist mental health midwives to combat post-natal depression: Government statement. $12^{\text {th }}$ November 2013. London: Department of Health.

Duckworth, M. P. \& Follette, V. M. (2012). Conclusions and future directions in the assessment, treatment, and prevention of retraumatization. In: Duckworth, M. P. \& Follette, V. M. (eds.). Retraumatization: assessment, treatment, and prevention. New York: Routledge; pp. 440-451.

Ehlers, A., \& Clark, D. M. (2000). A cognitive model of posttraumatic stress disorder' Behaviour Research and Therapy, 38(4), 319-345.

Ehlers, A., Clark, D. M., Hackmann, A., McManus, F. \& Fennell, M. (2005) 'Cognitive therapy for post-traumatic stress disorder: development and evaluation'. Behaviour Research and
Therapy, 43(4), 413-431.

Erskine, J. (2013). Treatment of post-traumatic stress disorder. In: Henderson, C., Smith, C., Smith. S. \& Stevens, A. (eds.) Women and psychiatric treatment: a comprehensive text and practical guide. Hove: Routledge. pp. 204-212.

Fenech, G., \& Thomson, G. (2014). Tormented by ghosts from their past: A meta-synthesis to explore the psychosocial implications of a traumatic birth on maternal wellbeing. Midwifery, 30(2), 185-193.

Finlay, L. (2011). Phenomenology for therapists: Researching the lived world. UK: John Wiley \& Sons.

Fisher, J. (2011). Sensorimotor approaches to trauma treatment. Advances in Psychiatric Treatment, 17(3), 171-177.

Forrester, M. A. (2010). Doing qualitative research in psychology: A practical guide. London: SAGE.

Furuta, M., Sandall, J., Cooper, D. \& Bick, D. (2016). Predictors of birth-related post-traumatic stress symptoms: secondary analysis of a cohort study. Women's Mental Health, 19(6), 987999.

Gamble, J. \& Creedy, D. (2004). Content and processes of postpartum counseling after a distressing birth experience: a review. Birth, 31(3), 213-218.

Gamble, J., Creedy, D. \& Moyle, W. (2004). Counselling processes to address psychological distress following childbirth: perceptions of midwives. Australian Midwifery, 17(3), 16-19.

Geller, P. A. \& Stasko, E. C. (2017). Effect of previous posttraumatic stress in the perinatal period' Journal of Obstetric, Gynecologic and Neonatal Nursing, 46(6), 912-922.

Giannouli, V. (2017). Ethnicity, mortality, and severe mental illness. The Lancet Psychiatry, 4(7), 517.

Giannouli, V. \& Stoyanova, S. (2018). Exploring emotional aspects of infertility in women from two countries. Psychiatrike= Psychiatriki, 29(1), 34-41.

Giannouli, V., \& Syrmos, N. (2019). Attitudes of younger and older adults towards kidney diseases in Greece. Health Psychology Research, 7(2), 8230.

Giannouli, V., Tegos, T., Zilakaki, M., \& Tsolaki, M. (2019). Elders and mental capacity: Using a qualitative approach to examine views on independence and protection across the Balkans. Hellenic Journal of Nuclear Medicine, 22, 122-139.

Giannoulis, K., \& Giannouli, V. (2020). Subjective Quality of Life, Religiousness, and Spiritual Experience in Greek Orthodox Christians: Data from Healthy Aging and Patients with Cardiovascular Disease. In GeNeDis 2018 (pp. 85-91). Springer, Cham.

Grigg, I. (2005). EFT in your pocket: tapping into emotional freedom. Plymouth: New Vision Media LLP.

Guest, G., Namey, E. E. \& Mitchell, M. L. (2012). Collecting qualitative data: a field manual for applied research. Thousand Oaks: SAGE.

Guy, K. \& Guy, N. (2009). Psychological trauma. Counselling at Work: BACP Journal. Spring (2009), 19-22.

Harris, K., Collinson, C. \& das Nair, R. (2012). Service $\square$ users experiences of an early intervention in psychosis service: an interpretative phenomenological analysis. Psychology and Psychotherapy: Theory, Research and Practice, 85(4), 456469.

Highsmith, S. (2016). Watching our words. Journal of Prenatal and Perinatal Psychology, 3(1), 45-65.

Hofmann, S. G., Asnaani, A., Vonk, I. J., Sawyer, A. T. \& Fang, A. (2012). The efficacy of cognitive behavioral therapy: a review of meta-analyses' Cognitive Therapy and Research, 36(5), 427-440. 
Human Rights Act (1998). London: Stationery Office.

Jones-Smith, E. (2011). Theories of counseling and psychotherapy: an integrative approach. London: SAGE.

Kershaw, K., Jolly, J., Kalvinder, B. \& Ford, J. (2005). Randomised controlled trial of community debriefing following operative delivery. British Journal of Obstetrics and Gynaecology, 112(11), 1504-1509.

King, S. (2015). Heal your birth, heal your life: tools to transform your birth experience and create a magical new beginning. Bristol: Silverwood Books.

Kleiman, K. (2017). The art of holding in therapy: an essential intervention for postpartum depression and anxiety. New York: Taylor \& Francis.

Krahn, G. L. \& Putnam, M. (2008). Qualitative methods in psychological research. In: Roberts, M. C. \& Ilardi, S. S. (eds.) Handbook of research methods in clinical psychology. Oxford: Blackwell Publishing; pp.176-195.

Lange, A., Ven, J. Q. V. D., Schrieken, B. A. L., Bredeweg, B., \& Emmelkamp, P. M. G. (2000). Internet-mediated, protocoldriven treatment of psychological dysfunction. Journal of Telemedicine and Telecare, 6(1), 15-21.

Lapp, L. K., Agbokou, C, Peretti, C. S. \& Ferreri, F. (2010). Management of post-traumatic stress disorder after childbirth: a review. Journal of Psychosomatic Obstetrics and Gynecology, 31(3), 113-122.

Littrell, J. \& Ashford, J. B. (1995). Is it proper for psychologists to discuss medications with clients? Professional Psychology: Research and Practice, 26(3), 238-244.

Lloyd-Evans, S. (2006). Focus groups. In: Desai, V. and Potter, R. (eds.) Doing developmental research. London: SAGE; pp.153162.

Lovell, K. \& Richards, D. (1995). Behavioural treatments in posttraumatic stress disorder. British Journal of Nursing, 4(16), 934-953.

Mason, Z., Cooper, M. \& Turner, H. (2012). The experience of pregnancy in women with a history of anorexia nervosa: an interpretive phenomenological analysis. Journal of Behavioral Addictions, 1(2), 59-67.

Mayer, S. J. (2015). Towards a relational understanding of embodied therapeutic relationships: a qualitative study of body-focused practitioners' experiences. Doctoral dissertation, University of the West of England. Available from: http://eprints.uwe.ac.uk/25656. Accessed 7th July 2017.

McBride, N. (2016). Intervention research: a practical guide for developing evidence-based school prevention programmes. Singapore: Springer.

McKenzie-McHarg, K. \& Poote, A. (2015). Dealing with posttraumatic stress disorder following childbirth' Perspective, 29, 20-26.

McKenzie $\square$ McHarg, K. (2004). Traumatic birth: understanding predictors, triggers, and counseling process is essential to treatment. Birth, 31(3), 219-221.

McLeod, J. (2013). An introduction to counselling. McGraw-Hill education (UK).

Merriam, S. (1995). What can you tell from an $\mathrm{N}$ of 1?: issues of validity and reliability in qualitative research. PAACE Journal of lifelong learning, 4(1995), 50-60.

Miller, R. L. \& Brewer, J. D. (2003). The A-Z of social research. London: SAGE.

Murphy, D., Archard, P. J., Regel, S. \& Joseph, S. (2013).A survey of specialized traumatic stress services in the United Kingdom. Journal of Psychiatric and Mental Health Nursing, 20(5), 433-441.
National Childcare Trust [NCT] (2015). Improved mental health provision is crucial for implementation of NICE guidelines' Perspective, 26, 10.

National Institute for Clinical Excellence [NICE] (2014). Antenatal and postnatal mental health: clinical management and service guidance. NICE guidelines [CG192]. London: NICE.

Neuman, W. L. (2011). Social research methods: qualitative and quantitative approaches, $7^{\text {th }}$ ed. Coventry: Pearson Education.

Newton, B. J., Rothlingova, Z., Gutteridge, R., LeMarchand, K. \& Raphael, J. H. (2012). No room for reflexivity? Critical reflections following a systematic review of qualitative research. Journal of Health Psychology, 17(6), 866-885.

Nicholls, K. \& Ayers, S. (2007). Childbirth-related post-traumatic stress disorder in couples: a qualitative study' British Journal of Health Psychology, 12(4), 491-509.

Patton, M. Q. (1991). Qualitative evaluation methods, $2^{\text {nd }}$ ed. Newbury Park: SAGE.

Pawar, M. (2004). Data collecting methods and strategies. In: Pawar, M. (ed.) Data collecting methods and experiences. Slough: New Dawn Press Group.

Peeler, S., Chung, M. C., Stedmon, J. \& Skirton, H. (2013). A review assessing the current treatment strategies for postnatal psychological morbidity with a focus on post-traumatic stress disorder. Midwifery, 29(4), 377-388.

Pennebaker, J. W. \& Chung, C. K. (2007). Expressive writing, emotional upheavals, and health. In: Friedman, H. S. \& Cohen Silver, R. (eds.) Foundations of health psychology. Oxford: Oxford University Press; pp.263-284.

Poleshuck, E. L. \& Woods, J. (2014). Psychologists partnering with obstetricians and gynaecologists. American Psychologist, 69(4), 344-354.

Porter, E. J. \& Cohen, M. Z. (2013) Phenomenology. In: Trainor, A. \& Graue, E. (eds.) Reviewing qualitative research in the social sciences. New York: Routledge; pp.180-196.

Rachman, S. \& Wilson, G. T. (2008). Expansion in the provision of psychological treatment in the United Kingdom. Behaviour Research and Therapy, 46(2008), 293-295.

Reed, M., Fenwick, J., Hauck, Y., Gamble, J. \& Creedy, D. K. (2014). 'Australian midwives' experience of delivering a counselling intervention for women reporting a traumatic birth. Midwifery, 30(2), 269-275.

Reeves, A. (2014). Dissemination of research. In: Vossler, A. \& Moller, N. (eds.). The counselling and psychotherapy research handbook. London: SAGE; pp.227-244.

Reid, K., Flowers, P., \& Larkin, M. (2005). Exploring lived experience. The Psychologist, 18(1), 20-23.

Rogers, C. R. (1957). The necessary and sufficient conditions of therapeutic personality change. Journal of Consulting Psychology, 21(2), 95-103.

Roller, M. R. \& Lavakas, P. J. (2015). Applied qualitative research design. A total quality framework approach. New York: The Guilford Press.

Rothschild, B. (2000). The body remembers: the psychophysiology of trauma and trauma treatment. New York: W. W. Norton.

Rowan, C., Bick, D. \& Bastos, M. H. (2007). Postnatal debriefing interventions to prevent maternal mental health problems after birth; exploring the gap between the evidence and UK policy and practice. Worldviews Evidence Based Nursing, 4(2), 97105.

Ruotsalainen, J. H., Verbeek, J. H., Mariné, A. \& Serra, C. (2014). Preventing occupational stress in healthcare workers. Cochrane Database System Review, 12(4), 1-155. 
Sandelowski, M. (1995). Sample size in qualitative research. Research in Nursing and Health, 18(2), 179-183.

Schank, J. A. and Skovholt, T. M. (1997). Dual-relationship dilemmas of rural and small-community psychologists. Professional Psychology: Research and Practice, 28(1), 44-49.

Schnurr, P. P., Friedman, M. J., Engel, C. C., Foa, E. B., Shea, M. T., Chow, B. K. \& Turner, C. (2007). Cognitive behavioral therapy for posttraumatic stress disorder in women: a randomized controlled trial. JAMA, 297(8), 820-830.

Scott, H. (2010). The medical model: the right approach to service provision? Helen Scott questions the medicalisation of mental distress, along with the use of labels to define illness, and argues that lip service is paid to service-user choice. Mental Health Practice, 13(5), 27-30.

Scullion, P. A. (2002), Effective dissemination strategies, Nurse Researcher, 10(1), 65-77.

Sheen, K. \& Slade, P. (2015). The efficacy of 'debriefing' after childbirth: is there a case for targeted intervention? Journal of Reproductive and Infant Psychology, 33(3), 308-320.

Shinebourne, P. (2011). The theoretical underpinnings of interpretative phenomenological analysis (IPA). Journal of the Society for Existential Analysis, 22(1), 16-31.

Simpson, M. \& Catling, C. (2015). Understanding psychological traumatic birth experiences: a literature review. Women and Birth, 29(3), 203-207.

Simpson, S.D. \& Dryden, W. (2011). Comparison between REBT and visual/kinaesthetic dissociation in the treatment of panic disorder: an empirical study. Journal of Rational-Emotive and Cognitive-Behavior Therapy, 29(3), 158-163.

Slade, P. \& Milby, E. (2017). Birth trauma and post-traumatic stress. In: Edozien, L. and O'Brien, P. M. S. (eds.) Biopsychosocial factors in obstetrics and gynaecology. Cambridge: Cambridge University Press; pp.348-358.

Slater, P. M. (2015). Post-traumatic stress disorder managed successfully with hypnosis and the rewind technique: two cases in obstetric patients. International Journal of Obstetric Anesthesia, 24(3), 272-275.

Sltibniewski-Woods, D. (2011). A review of postnatal debriefing of mothers following traumatic delivery. Community Practitioner, 84(12), 29-31.

Smith, D. W. (2011). The phenomenology of consciously thinking. Cognitive Phenomenology, 345-72.

Smith, J. A., Flowers, P., \& Larkin, M. (2009). Interpretative phenomenological analysis: theory, method, research. London: SAGE.

Smith, J. A., \& Osborn, M. (2007). Pain as an assault on the self: An interpretative phenomenological analysis of the psychological impact of chronic benign low back pain. Psychology and Health, 22(5), 517-534.

Soet, J. E., Brack, G. A. \& DiIorio, C. (2003). Prevalence and pre- dictors of women's experience of psychological trauma during childbirth. Birth, 30(1), 36-46.

Sommers-Flanagan, J. \& Sommers-Flanagan, R. (2015). Counseling and psychotherapy theories in context and practice: skills, strategies, and techniques. Hoboken: John Wiley \& Sons.

Speier, D. S. (2017) Birth trauma. In: Leach, P. (ed.) Transforming infant wellbeing. Research, policy and practice for the first 1001 critical days. Abingdon: Routledge; pp.107-116.

Stoyanova, S. Y., Giannouli, V., \& Gergov, T. K. (2017). Sentimentality and nostalgia in elderly people in Bulgaria and Greece-Cross-validity of the questionnaire SNEP and crosscultural comparison. Europe's Journal of Psychology, 13(1), 109-128.

Teddlie, C. \& Tashakkori, A. (2009). Foundations of mixed methods research: integrating quantitative and qualitative approaches in the social and behavioral sciences. Thousand Oaks: SAGE.

Thomson, G. M. \& Downe, S. (2010). Changing the future to change the past: women's experiences of a positive birth following a traumatic birth experience. Journal of Reproductive and Infant Psychology, 28(1), 102-112.

Turkstra, E., Creedy, D. K., Fenwick, J., Buist, A., Scuffham, P. A. \& Gamble, J. (2015). Health services utilization of women following a traumatic birth. Archives of Women's Mental Health, 18(6), 829-832.

Van Emmerik, A. A., Kamphuis, J. H. \& Emmelkamp, P. M. (2008). Treating acute stress disorder and posttraumatic stress disorder with cognitive behavioral therapy or structured writing therapy: a randomized controlled trial. Psychotherapy and Psychosomatics, 77(2), 93-100.

Watzlawik, M. \& Born, A. (2007). Capturing identity: Quantitative and qualitative methods. Lanham: University Press of America.

Wells, A. \& Colbear, J. (2012). Treating posttraumatic stress disorder with metacognitive therapy: a preliminary controlled trial. Journal of Clinical Psychology, 68(4), 373-381.

White, T., Matthey, S., Boyd, K. \& Barnett, B. (2006). Postnatal depression and post-traumatic stress after childbirth: prevalence, course and co-occurrence. Journal of Reproductive and Infant Psychology, 24(02) pp.107-120.

Willig, C. (2008). A phenomenological investigation of the experience of taking part in extreme sports. Journal of Health Psychology, 13(5), 690-702.

Zimmerman, M. A. (2013). Resiliency theory: A strengths-based approach to research and practice for adolescent health. Health Education \& Behavior, 40(4), 381-383. 